REFERENCE

A 11105 851480

\title{
NBS Research \\ Reports
}

NIST

PUBLICATIONS

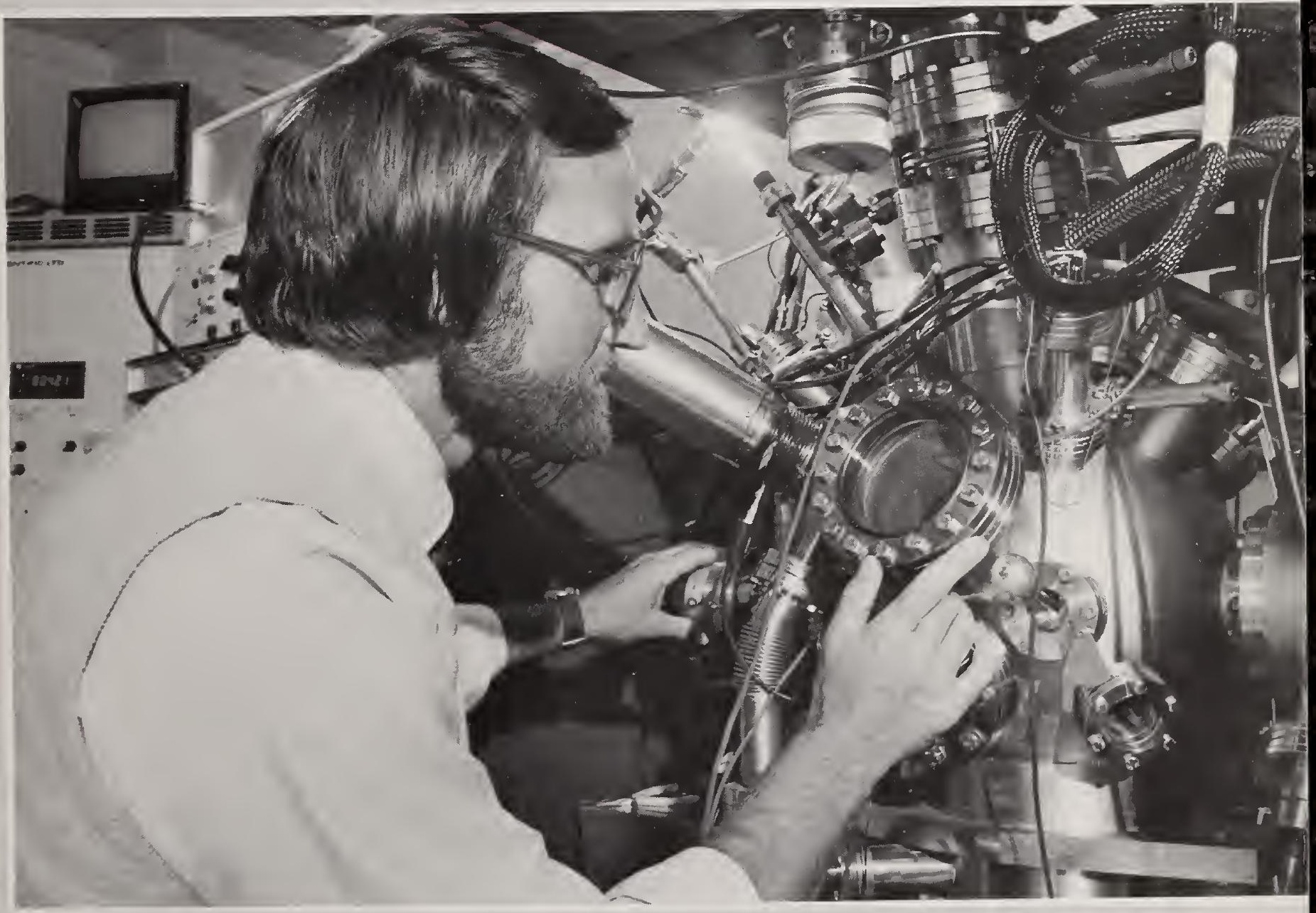

U.S. DEPARTMENT OF COMMERCE NATIONAL BUREAU OF STANDARDS NBS SPECIAL PUBLICATION 719

QC

100

.057

N0.719

1986 
Cover photo: Through the use of very thin flims and detailed surface analysis, Dr. Stephen Semancik and his colleagues have characterized the surface adsorption properties of tin oxide. Such information can be used to improve tin oxide sensors. See page 16. 


\section{CONTENTS}

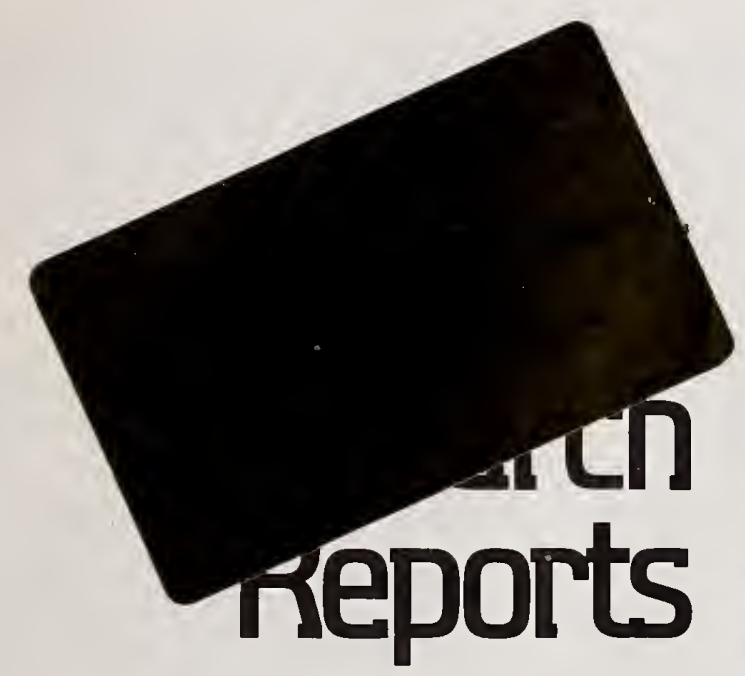

NBS Research in Biotechnology: Providing the Scientific Fundamentals

New Publications

Conference Calendar

Research Update

Spirit of Cooperation Alive and Well

at National Bureau of Standards

Taking the Earth's Measure at a Unique Institution

Gravity, When You Get Right Down to It

The Light Fantastic

Safer, Quicker Ways to Prepare Samples for Chemical Analysis

Researchers Study the Process to Improve Measurement Accuracy

Expanded Version of IGES Standard Available 16

21

NBS Studying New Technique to Identify Irradiated Foods

22

30

32

U.S. DEPARTMENT OF COMMERCE

Malcolm Baldrige, Secretary

National Bureau of Standards

Ernest Ambler, Director

National Bureau of Standards

Gaithersburg, MD 20899

301/921-1000

National Bureau of Standards

Boulder, CO 80303

$303 / 497-3000$

July 1986

NBS Special Publication 719

Prepared by the Public Information Division

A903 Administration Building

National Bureau of Standards

Garthersburg, MD 20899

301/921-318

Library of Congress

Catalog Card Number:

86-600556

CODEN:XNBSAV

Any mention of commercial products is for information only; it does not imply recommendation or endorsement

by the National Bureau of Standards

nor does it imply that the products

mentioned are necessarily the best

available for the purpose. 


\section{BS, QINT DATABASE SYSTEMS TO STUDY "DATA \\ ENGINEERING" TOOLS \\ NBS and QINT Database \\ Systems Corporation have}

begun a joint research program to develop an "Information Engineering Workstation"

to complement the NBS Automated Manufacturing Research Facility (AMRF) project. QINT, which sells an automated software package implementing a sophisticated data analysis methodology and providing a formal representation for it, will assist NBS researchers in adapting and extending their analysis tools for use with the NBS Integrated Manufacturing Data Administration System (IMDAS). The QINT tools ensure that the implemented databases accurately reflect the data analysis. The Information Engineering Workstation, using graphic aids, will allow an analyst to define the data shared within the AMRF and generate automatically the data structures necessary for IMDAS data directories and databases. Gail Vermilyea and B. Benita Ranghel of QINT will work with the NBS Factory Automation Systems Division under the Bureau's Research Associate Program. Through the NBS Research Associate Program, researchers from industry and other sponsoring organizations, whose salaries are paid by their sponsors, work at NBS on projects of mutual interest.

\section{ROCESS CONTROL SENSOR GOAL OF COOPERATIVE PROGRAM}

The Aluminum Association and NBS have agreed to a cooperative research program to develop a process control sensor for the manufacture of extruded aluminum products. Extruded shapes, bars, pipes, and rods represented nearly one-fifth of the estimated 15.2 billion pounds of aluminum shipped by industry in 1985. As a part of the agreement, a research associate sponsored by the Aluminum Association will work at the Bureau evaluating and using NBS research results to develop a "noncontact" process

control sensor for measuring internal temperatures during the rapid extrusion of aluminum alloys.

The second phase of the cooperative program calls for installing a prototype sensor at a plant for field evaluation with an aluminum extrusion process. Instrument builders will be offered opportunities to participate in the demonstrations and to investigate the sensor's performance with various automaied process control systems. The sensor also will be evaluated for use in controlling temperatures in other areas of aluminum processing such as the preheating of billets and ingots, at quenching facilities, and for controlling continuous casting.

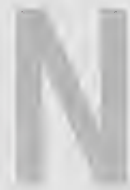

\section{EW MATERIAL TO IMPROVE MEASUREMENTS OF PCB LEVELS IN BLOOD}

Tests for amounts of polychlorinated biphenyls (PCB's) in blood samples can be checked for accuracy with a Standard Reference Material (SRM) available from NBS. Such tests are important for determining exposure of persons who work with toxic PCB compounds-employees in the chemical industry or emergency personnel who clean up chemical spills, for example. SRM 1589 is in the form of freeze-dried human blood serum "spiked" with 106 nanograms of Aroclor 1260 per gram of serum. (Aroclor 1260 is a mixture of PCB's found in some transformer oils). The SRM is intended for use in the calibration of analytical instruments and validation of a laboratory's procedure for measuring PCB's in blood. It also may be used as a primary standard against which secondary reference materials may be compared Certified to be accurate within a 1 percent range, the SRM costs $\$ 163$ per three-vial set. To order SRM 1589, Polychlorinated Biphenyls (as Aroclor 1260) in Human Serum, or for more information about the more than 900 SRM's the Bureau offers for sale, contact the Office of Standard Reference Materials, B311 Chemistry Building, NBS, Gaithersburg, MD 20899 , 301/921.2045
U NDERWRITERS LABORATORIES, NBS AGREE ON JOINT PROGRAM

Underwriters Laboratories is sending one of its researchers to work at NBS laboratories to study false alarms by smoke detectors. While detectors are used in millions of residences as well as commercial and institutional buildings, false alarms from the detectors reduce their effectiveness and consumer confidence. The research, which will be conducted under the NBS Research Associate Program, will involve visits to selected installations that have experienced problems and testing at NBS and other facilities. It also will include identifying problems and coordinating activities with equipment manufacturers testing laboratories, and standards and code organizations. Through the NBS Research Associate Program, researchers from industry and other sponsoring organizations, whose salaries are paid by their sponsors, work at NBS on projects of mutual interest.

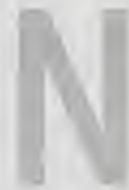

\section{BS VALIDATING COMPUTER SECURITY DEVICES}

Researchers in the NBS Institute for Computer Sciences and Technology have completed the first validation of a security device that will be used to authenticate electronic funds transfer messages. The validation program is part of an agreement signed by NBS, the Department of the Treasury, and the National Security Agency (NSA) in March 1985 to help protect the billions of dollars in federal funds that are transferred electronically each year. Based on technical guidance from NBS and NSA, the Treasury Department will certify that electronic funds transfer devices are designed properly and security features called for in a 1984 Treasury Department directive have been incorporated.

NBS developed the test methods to validate that the devices comply with federal and industry standards (Federal Information Processing Standard 113, Computer Data Authentication, and American National Standard for Financial Institution Message Authentication 
[Wholesale]). The validation system can be used to test equipment remotely through an electronic interconnection with NBS. For further information or to validate security devices, contact Miles Smid, A216 Technology Building, NBS, Gaithersburg, MD 20899, 301/921-3427.

\section{MPROVED GC/MS METHODS AID STUDY OF DNA RADIATION DAMAGE}

A novel application of analytical techniques allows NBS researchers to achieve very high levels of sensitivity in their study of radiation-induced damage in DNA. Identification and measurement of radiation-altered biomolecules is part of an overall NBS program to understand the fundamental physical and chemical interactions of ionizing radiation with matter. The quantitative measurement of these molecular alterations is a necessary first step in learning how ionizing radiation causes changes in DNA that might have detrimental consequences in living cells.

Radiation chemist Miral Dizdaroglu has detected altered nucleosides in DNA molecules irradiated at doses as low as 1 Gray (100 rads) in concentrations as low as 10 femtomoles (0.01 part per trillion). Dizdaroglu's method involves using enzymatic hydrolysis to break down DNA to its component nucleosides. Combined gas chromatography/mass spectrometry with selected ion monitoring (SIM) is then used to identify those species altered by exposure to radiation. The use of the mass spectrometer's SIM mode requires that the mass spectrum of the DNA nucleoside under investigation and its gas chromatographic retention time be known in advance, but allows at least a 100-fold increase in sensitivity. This permits study of nucleosides at very low concentrations in mixtures too complex for analysis by gas chromatography alone.

\section{ENSOR DEVELOPED TO} IMPROVE QUALITY CONTROL OF PROCESSED METALS

A new ultrasonic sensor for measuring the depth and properties

of treated steels and metal alloys has been developed at NBS to improve quality control of processed metals. The sensor, which uses ultrasonic waves to make very precise measurements of both the depth and mechanical properties of surfacemodified layers, eliminates the need to destroy finished products to determine the effectiveness of processes used to modify metal surfaces and the quality of the component. The sensor was developed by two guest workers from Johns Hopkins University, Dr. Moshe Rosen, professor of materials science, and graduate student Bret J. Elkind and NBS scientist Dr. Haydn N.G. Wadley. The sensor has been evaluated in a series of laboratory tests at NBS to verify its accuracy and performance. The researchers anticipate the new ultrasonic sensor will become an importarit measurement tool for manufacturers using nondestructive evaluation techniques to improve the quality control of their products.

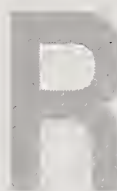

EFERENCES AVAILABLE FOR MEASURING AIRBORNE BERYLLIUM AND ARSENIC

Laboratories that analyze levels of beryllium and arsenic in industrial atmospheres can check the accuracy of their equipment and analytical methods with a Standard Reference Material (SRM) available from NBS. Tests to determine airborne levels of these two potentially toxic metals in workplace environments-in certain mining and pesticide industries, for example-are crucial for monitoring worker exposure and are required periodically by the federal Occupational Sairety and Health Administration. The new NBS material, Beryllium and Arsenic on Filter Media (SRM 2677), will allow verification of such tests. It is designed to be run through the same chemical tests as an actual air sample collected on a filter. The SRM, which contains two identical sets of four mixed cellulose ester membrane filters, is certified for accurate amounts of beryllium and arsenic composite at three different levels. Included in the sets are two "blank" filters to gauge the ambient levels of beryllium and arsenic in the laboratory where the analysis is made. SRM 2677 costs $\$ 118$ and is available from the Office of Standard Reference Materials, B311 Chemistry Building, NBS, Gaithersburg, MD 20899, 301/921-2045.
OOPERATIVE RESEARCH AGREEMENTS FOR SEMPA FACILITY SOUGHT

NBS is seeking firms interested in cooperative research agreements to further develop and exploit the Bureau's new facility for scanning electron microscopy with polarization analysis (SEMPA). SEMPA allows the simultaneous observation of surface microstructure and surface magnetic domains at the resolution of electron microscopy (0.01 micron), using an innovative, extremely compact electron spin detector invented at NBS. The Bureau's unique SEMPA facility can be used for research in magnetic thin films high-coercivity magnetic materials, highdensity magnetic storage media, and other advanced magnetic materials. NBS would like to set up joint research programs on projects of mutual interest on a cost-sharing basis. For more information, contact $\mathrm{Dr}$. Robert Celotta, B210 Metrology Building, NBS, Gaithersburg, MD 20899, 301/921 2051.

\section{EST METHOD FOR PHYSICAL LAYER PROTOCOL BEING DEVELOPED}

The NBS Institute for Computer Sciences and Technology (ICST) is developing a test method to ensure that modem and head-end equipment from different manufacturers can communicate using an IEEE standard (802.4 Broadband Token-Passing Bus physical layer protocol) By transmitting and receiving various test frames, modems from various manufacturers will be tested against head-end equipment from other manufacturers. The equipment, donated by industry, will be tested in ICST's local networking laboratory. NBS has been working with industry and standards groups for several years to make it possible for computer systems or equipment to communicate with each other regardless of who manufactures the individual pieces. The NBS test methods make it possible for vendors to know whether the complex "protocols," or rules which make possible multi-vendor computer-to-computer communication, are being implemented correctly. 


\section{Spirit of Cooperation Alive and Well at National Bureau of Standards}

e want to be sure our research is helping industry solve its measurement problems, and one of the most effective ways to accomplish that is through cooperative programs," says Dr. Ernest Ambler, director of the National Bureau of Standards. Each year more than 900 people from industry, universities, and other government agencies work side-by-side with NBS scientists and engineers on a wide range of research projects including robotics, computer networks, clinical chemistry, and ceramics.

The arrangements are mutually beneficial. "Successful relations between government and the private sector don't have to be based on grants and government giveaways," says Dr. Donald Johnson, director of the NBS National Measurement Laboratory.

"Our experience at NBS is that these programs work best when both sides are involved in a personal way, supplying staff and resources, and when both sides get something they want out of the relationship."

The visiting researchers get an opportunity to work with the scientists and engineers at NBS many of whom are renowned experts, and to use the Bureau's premier research and testing facilities. They then can take the newly developed technology back to their organizations to be incorporated into new ideas, new processes, and new products. Says Ambler, "They come to NBS to conduct research, but they also come to learn how they can put our work to use." NBS gains from these cooperative programs by learning firsthand the views and needs of industry.

"To ensure our domestic strength and to compete successfully with other nations, we must exploit our knowledge and technology. That means we must make the most of our research resources-both our equipment and our people," adds Ambler. "Cooperation in research and development is one obvious answer. We at NBS have made cooperation with industry a way of doing business right from the start, and now, to help meet these economic challenges, we are working to do even more."

As the only federal laboratory with the explicit goal of serving U.S. industry and science, NBS uses a wide variety of mechanisms to transfer its expertise in measurement technology to those who need it.

\section{Robots and Computers}

Private companies, universities, and other government agencies are working with NBS to develop the Automated Manufacturing Research Facility (AMRF). The AMRF, a research testbed for the factory of the future where robots and machine tools work together under

"We at NBS have made cooperation with industry a way of doing business right from the start, and now, to help meet these economic challenges, we are working to do even more.'

computer control, is being built at NBS to study fundamental questions affecting factory automation. Questions that affect the modernization and competitiveness of American industry.

Since 1982, 35 companies have paid more than 50 of their researchers to work in the AMRF and about $\$ 4.6$ million worth of equipment and software has been loaned or donated to NBS by industry for this project. The Navy Manufacturing Technology Program is a major partner in the facility, and the Air Force Intelligent Task Automation Project and other government agencies also have sponsored specific parts of the AMRF effort. In addition, a number of universities have contributed to the project by loaning guest researchers.

Together these researchers are experimenting with methods for getting robots, computers, and machine tools from different manufacturers to communicate and work together in an integrated system. Their other primary goal is to find a means for controlling quality in a fully automated factory environment.

All of this will give companies, in particular small firms with less than 50 employees, the flexibility to buy equipment from different manufacturers at different times with the assurance that the machines they buy can be made to work together without expensive, custom-designed interfaces.

According to a study by the Management Collaborative Group of Chapel Hill, N.C., the contribution of the AMRF to the increased use of numerical-control (NC) machine tools in U.S. industry will produce a savings to the metalworking industry of between $\$ 250$ and $\$ 760$ million per year by 1990 . The study also predicts that the U.S. Navy's support of the AMRF will improve defense readiness. It says the annual Department of Defense procurement savings generated by increased use of NC machine tools, resulting from the AMRF work, will total an estimated $\$ 154.8$ million-four times the Navy's total projected investment-by the end of 1989.

American companies are already adopting the ideas and techniques of the AMRF. One company has adapted NBSdeveloped error-correction techniques to the control system of its machining centers. 
Another has developed a version of "Drill-Up"-a device built by NBS engineers to help sense when a drill bit is about to break. And the U.S. Navy is now undertaking a model project to transfer the technology into a Navy shipyard.

In another program, NBS is participating in the international effort to establish computer networking standards to improve communication among different computers. Since 1979, NBS has been doing the technical spade work-developing the data, testing the theories, making sure proposed standards will work - to aid in the voluntary standards development process. In this effort, NBS computer experts have worked closely with industry and standards groups: Over the past several years, visiting researchers from about $25 \mathrm{com}$ panies such as Intel, General Motors, and Honeywell have aided in the development of networking standards as well as test methods needed by industry to determine whether the standards have been used correctly, thus enabling different manufacturers' equipment to work together.

NBS also has been instrumental in getting these standards and test methods out of the laboratory and into use through workshops to transfer the technology to the vendors and users. More than 175 companies and organizations have participated in these workshops. The technology has been used successfully at two major showings: the 1984 National Computer Conference and the 1985 Autofact exhibit. Industry also has adopted the technology as standards for the plant floor and engineering and office environments. Both the Manufacturing Automation Protocol (MAP) and the Technical and Office Protocol (TOP) were demonstrated at the Autofact exhibit.

Says Mike Kaminsky, manager of the MAP program at General Motors, "It's my firm belief that

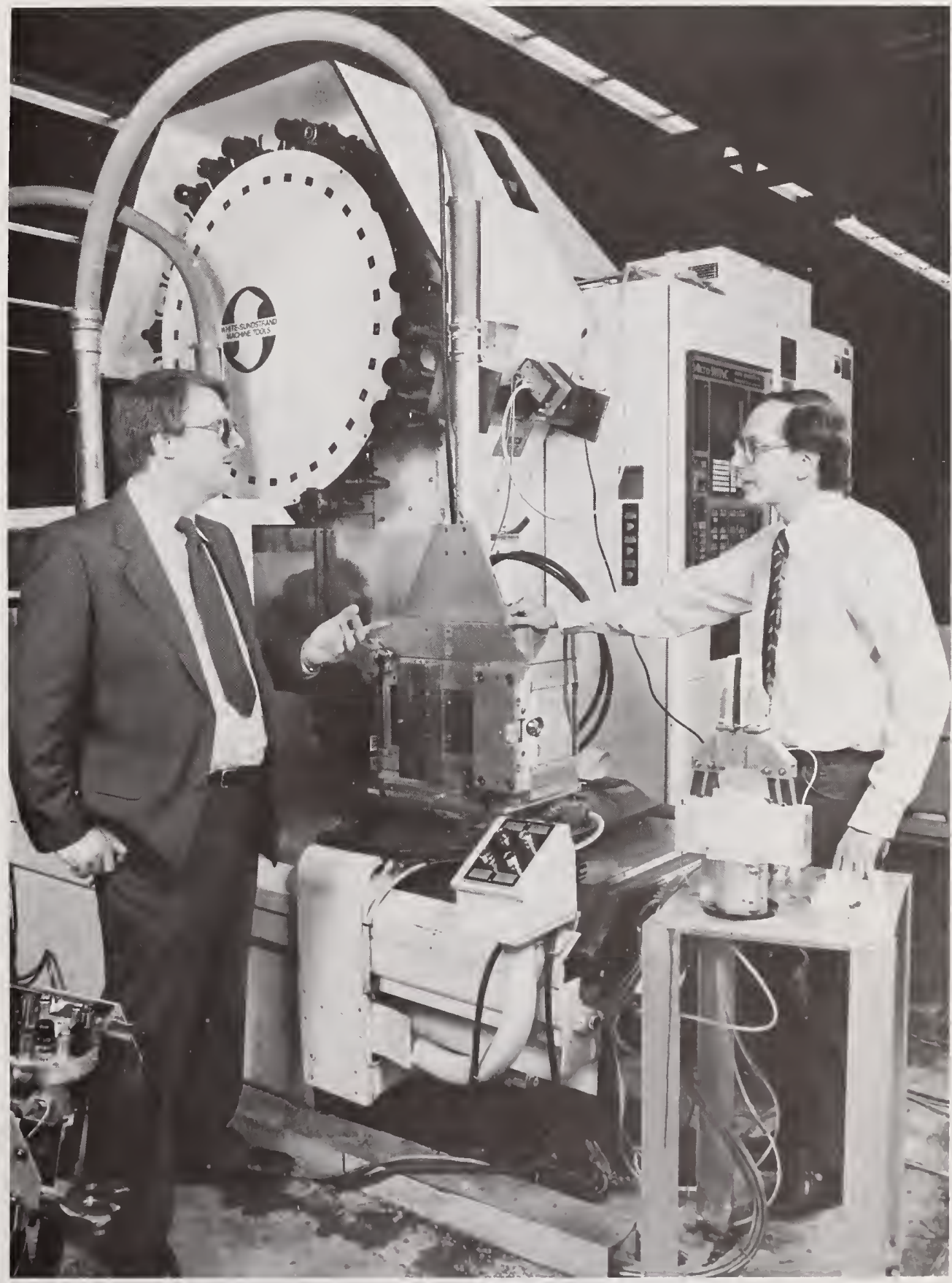

At the horizontal workstation in the NBS Automated Manufacturing Research Facility, Christopher Stevenson (left) of White-Sundstrand and Howard Harary of NBS discuss the next generation of machine tools. 


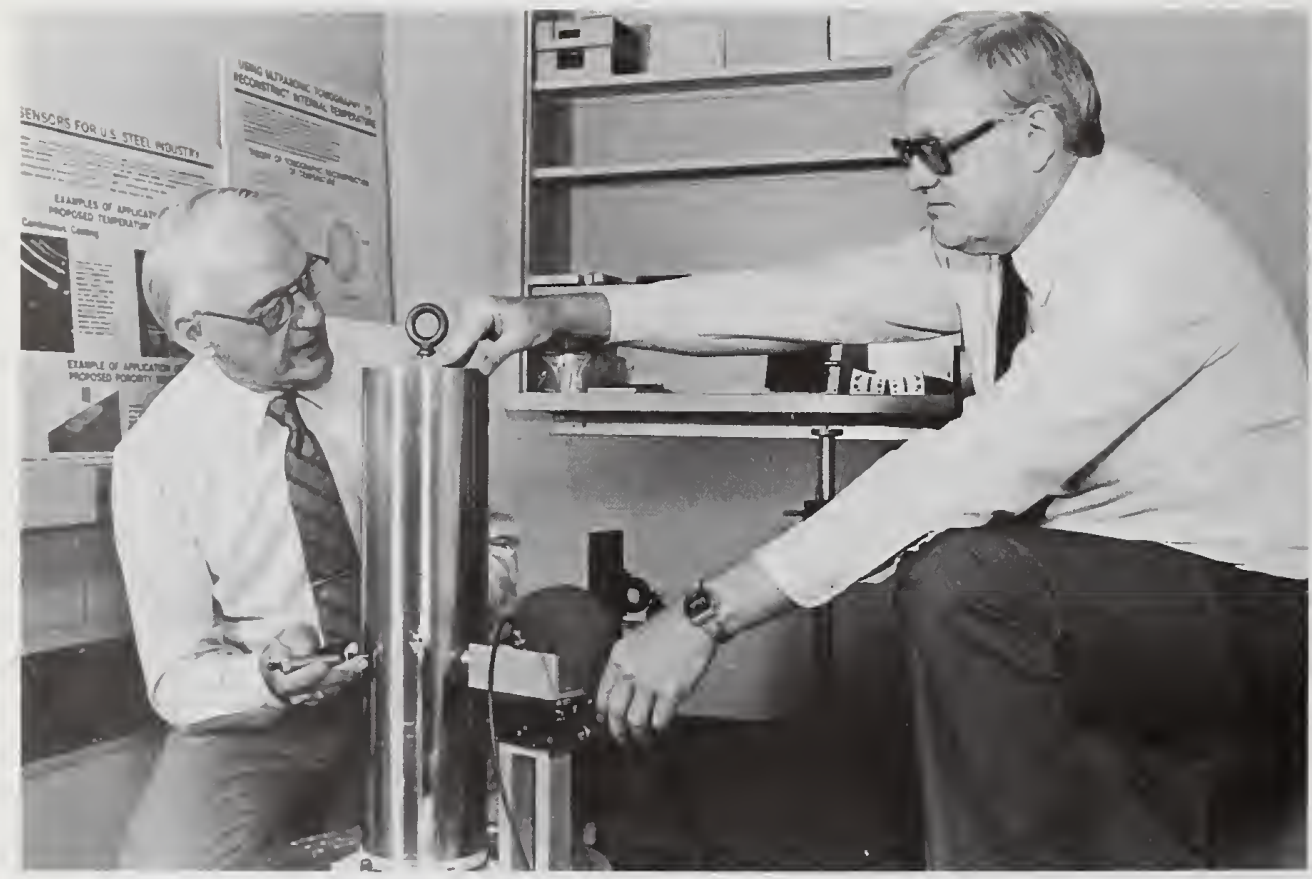

NBS metallurgist Floyd A. Mauer (left) and David Rogers, AISI research associate from U.S. Steel, are working on sensors to improve steel production.

without NBS involvement in developing and testing these standards and getting them accepted by vendors and users we would not be at the point we are today. NBS has been the catalyst that has brought all this together

"It is really a two-way street," adds Dr. John Heafner, chief of the Systems and Network Architecture Division at NBS. "The companies have a vested interest in making it easier for computer systems and equipment to communicate-it's vital to the industry. And we can't afford to work on these kinds of projects without knowing what industry is doing and how we can best serve them. We need industry's involvement, and key companies are making the kinds of contributions that will mean our work will pay quick dividends."

\section{Improving Steel and Clinical Measurements}

For years NBS and the metals industry have collaborated to improve the durability and performance of metals and alloys. As early as 1903 , NBS was working to determine the melting points of pure metals as a part of the Bureau's mission to perform basic measurements.

Today, the American Iron and Steel Institute (AISI), the American Society for Metals, the National Association of Corrosion Engineers, and others are sponsoring researchers to work with NBS scientists and engineers on generic technology and reliable data to upgrade the quality of metals and improve productivity for the metals industry.

For instance, AISI is currently sponsoring five researchers from United States Steel, LTV Steel, and Bethlehem Steel Corporation in a project to develop a new sensor that promises to save steel mills millions of dollars. The sensor technique should enable steel producers to detect quickly flaws in hot metal and more accurately crop unsound material before it is run through the complete production cycle. The sensor has been tested successfully at the Argonne National Laboratory, a Department of Energy facility, and in the near future will undergo final tests in a steel mill.

Dr. Lyle H. Schwartz, director of the NBS Institute for Materials Science and Engineering, says, "This cooperative program between industry and two national laboratories gave the private sector an opportunity to participate at the very beginning of the research process. This will help to ensure acceptance of the research results and assist in the successful transfer of the technology to users. Technology transfer is the vital link in the research process.

in some cases, NBS works with a group, or consortium, of companies to solve a particular problem. For example, NBS and several companies have joined in an effort to better clinical measurements. The focus of this joint agreement is the measurement of two elements-sodium and potassium-important in clinical tests because of their roles in high blood pressure, heart disease, and general health. The National Committee for Clinical Laboratory Standards, on behalf of the corporations, has sent a researcher to NBS as part of the agreement. Major questions about measuring these elements are being examined. The industrial consortium, which includes instrument manufacturers and others involved with clinical measurements, is contributing funds for the project.

\section{Biotechnology and Astrophysics}

In a first-of-its-kind agreement for NBS, the Bureau, the University of Maryland, and Montgomery County, Maryland, are establishing a Center for Advanced Research in 
Biotechnology (CARB) to provide a forum for collaborative research among academic, government, and industrial scientists. "We will focus on establishing the world's finest facility for determining and analyzing the structure of macromolecules," says Dr. Kevin Ulmer, director of the center. "The ultimate goals of CARB's research are to radically reduce the time and effort required to determine the atomic structure of proteins and to effectively model and predict their properties."

CARB researchers will draw upon the expertise at NBS in physical and chemical measurement technology and will have access to unique research facilities including the Bureau's research reactor and supercomputer. The center will house scientists from the University of Maryland and NBS as well as a large population of visiting scholars, industrial fellows, and graduate and postdoctoral students Eventually about 130 scientists are expected to be working at the center.

Hiring of senior research scientists for CARB is under way and construction of the building, being financed by Montgomery County, is scheduled to begin this fall.

Although the biotechnology center agreement is unique, NBS has a long history of cooperative research with universities. Witness the 24-year-old enterprise known as the Joint Institute for Laboratory Astrophysics-or JILA-formed between NBS and the University of Colorado. (See article on page 9.) JILA was originally created to help provide sound laboratory techniques and measurements needed by space scientists to understand the behavior of atoms or molecules in different atmospheres. The work of JILA scientists has been used in a diversity of practical applications from the design of new, more powerful lasers to the building of high-voltage electrical generators and more efficient street lights.

A permanent Ph.D. staff of 22 "fellows" manages the day-to-day operation of JILA-8 are full-time university faculty and 14 are NBS scientists. But through a rather complicated system that brings together renowned scholars from around the world, graduate and postdoctoral students, and visiting scientists, NBS gets the benefits of the work of 160 people. The university gains a large community of international scholars and a substantial adjoint faculty which trains graduate students, teaches courses, and serves on committees.

\section{Sharing Facilities}

Most of the Bureau's research and testing facilities are available for cooperative research by the scientific and engineering communities, and, in certain cases, companies can use NBS facilities for proprietary research. "We have decided to make selected NBS facilities available to U.S. researchers for proprietary work on a costrecovery basis, when equal or superior facilities are not otherwise available," says Ambler. "We hope this policy will increase the transfer of technology to industry and encourage commercially important research that might otherwise not be done.'

Three hundred people from 60 institutions, including other government agencies, universities, and industry, conduct research annually at the NBS 20-megawatt research reactor, which is available for both cooperative and proprietary research. The Food and Drug Administration, for example, uses the NBS reactor to measure small quantities of toxic materials in food, drugs, laundry aids, and cosmetics. The Smithsonian Institution has used it to examine works of art, E.I du Pont de Nemours and Company to measure trace elements in Teflon, and General Electric Company to study tiny flaws in jet engine turbine blades.

NBS is now installing a coldneutron source at the reactor that will improve greatly its effectiveness and versatility. With the coldneutron source, researchers will be able expand studies in materials research to include investigations of magnetic properties of new advanced alloys; measurements of crack growth or the nature of voids in new, experimental ceramics; and the distribution of "doping" elements in

\section{CARB researchers will draw upon the expertise at NBS in physical and chemical measurement technology and will have access to unique research facilities.}

semiconductor materials in concentrations below 1 part in a million.

A unique agreement between NBS and Exxon Research and Engineering Company calls for the development of a new smallangle neutron scattering (SANS) instrument at this cold-neutron source. SANS is a method of using relatively low-energy neutrons as probes to measure the structure of materials in very great detail. The new instrument will offer a more extensive range of capabilities than the existing SANS at NBS. Exxon and NBS each will have the right to one-third of the available time on the instrument and the remaining one-third will be available for use by third parties.

NBS has just developed a brand new facility for studying advanced 


\section{Whom to Call}

One of the most popular ways to make NBS research and facilities accessible to U.S. industry is through the Industrial Research Associate Program. Under this program, which NBS has run since the 1920's, scientists and engineers from industry, trade associations, technical societies, and other organizations work side-by-side with NBS researchers. With their salaries paid by their employers, the associates work at NBS, usually for 1 to 3 years on a wide range of research including robotics, computer networks, dental materials, and ceramics. For further information, contact the Office of Research and Technology Applications-301/921-2226.

\section{Proprietary Facilities}

While most NBS facilities are available for cooperative research, in 1985 the Bureau opened up some of its unique facilities for proprietary research. NBS makes these facilities available under certain conditions to support U.S. industry in its development of new competitive products and processes.

One facility which is available for proprietary research is the NBS research reactor. It is used to conduct research in a variety of areas such as materials science, element analysis, and nondestructive evaluation. Twenty-five experimental stations are available at the reactor.

In addition to the reactor, NBS has made available a large environ mental chamber and an electron linear acceierator (LINAC). The environmental chamber is capable of accommodating objects up to the size of a two-story house under simulated environmental conditions, and the LINAC provides the capability for conducting precision research with high-energy beams of electrons, photons, and neutrons and for developing measurement standards for these types of radiation. The LINAC presents special opportunities for small businesses that lack ready access to radiation-processing facilities. For further information, contact the NBS Program Office-301/921-3137.

\section{Other Arrangements}

For information on arranging a cooperative program in a particular research area at NBS, contact the individual institute or laboratory:

$\square$ Institute for Materials Science and Engineering, 301/921-2891:

Provides measurements, data, standards, reference materials, and other technical information regarding materials to industry, government agencies, universities, and other scientific organizations.

$\square$ National Measurement Laboratory, 301/921-2828: Provides the national system of physical and chemical measurements; coordinates the system with measurement systems of other nations; and furnishes essential services leading to accurate and uniform physical and chemical measurements throughout the nation.

$\square$ Institute for Computer Sciences and Technology, 301/921. 3151: Provides the standards, specifications, measurement and test methods, and technical guidance needed by government and industry to make better use of computer hardware, software, networks, and security.

$\square$ National Engineering Laboratory, 301/921-3434 Conducts research in engineering and applied science. Studies problems in electronics, manufac. turing automation, chemical engineering, the behavior (and prevention) of fires, and the design and construction of buildings. magnetic materiais and would like to set up joint research programs on projects of mutual interest on a cost-sharing basis. The SEMPA facility (Scanning Electron Microscopy with Polarization Analysis) allows researchers to observe simultaneousiy the magnetic character of a surface and its physical structure over dimensions as small as 100 angstroms (10 nanometers). This new research tool is expected to have important applications in a number of fields, including the development of highdensity magnetic recording media and smail, high-efficiency electric motors.

These are just a sampling of the many cooperative research programs that NBS has with industry, academia, and other government agencies. NBS also provides other opportunities to transfer the Bureau's expertise in measurement technology to those who need it. Literally hundreds of conferences, workshops, and seminars are held each year by NBS. Bureau researchers publish their work as broadly as possible and work actively with professional and technical societies and standards organizations. Using videotapes to explain NBS research enables others who cannot visit NBS or attend conferences to take advantage of NBS research. In addition, many of NBS' databases and experts are being made available through computer technology, so that others will be able to tap into even more information.

While NBS Director Ambler is proud of the Bureau's record of cooperation, he would like to pursue more avenues for joint research and services. "By increasing industry's access to our advanced measurement capabilities, we hope to help industry improve its products and processes and thus its international competitiveness."

by Jan Kosko

NBS Public Affairs Specialist 


\section{Taking the Earth's Measure at a Unique Institution}

as the distance from the center of the Earth changed? Can we measure that change to the nearest centimeter? Why does the aurora borealis glow the way it does? How do you build an instrument $1,000,000$ kilometers long to measure gravity waves?

What's the best gas to use in high-intensity outdoor street lights? What, for that matter, is darker than dark? How do you tell if terrorists are tunnelling into a nuclear weapons vault?

You might guess that this jumble of questions arose from the writing of a multi-volume encyclopedia. in fact, they represent only part of the unexpected diversity of research topics at a unique, little-known organization-the Joint Institute for Laboratory Astrophysics in Boulder, Colo.

The "joint institute" part is easy enough. JILA, as it is called around the world, is a 24-year-old cooperative research effort between the federal government's National Bureau of Standards (NBS) and the state-run University of Colorado (CU). Laboratory astrophysics? That's a bit harder.

"When JILA was first founded it was a child of the space program," explains Dr. Katharine Gebbie, who manages the NBS half of the institute. "We were going to be sending up rockets, looking at stars and the Earth's atmosphere. A study by the National Academy of Sciences about 1960 pointed to serious gaps in our basic understanding of the behavior of atoms and molecules in atmospheres, whether on Earth, other planets, the Sun, or stars."

JILA was originally created to help fill those gaps by providing the sound laboratory techniques and measurements needed by space scientists.

In much of this research, the basic idea is simple (although the details are rather difficult). Atoms and molecules can be distinguished by their spectra-the characteristic frequencies in the electromagnetic spectrum that they emit or absorb. Since all we really know about a star is its apparent electromagnetic spectrum and its position in the sky, spectroscopy becomes an extremely important tool for astronomy and astrophysics. Spectroscopy can tell us much more than simply what atoms are present in a gas. Energy levels, temperatures, and chemical and physical reactions can all be deduced from spectra, given that you know what to look

\section{JILA was originally created to help fill those gaps by providing the sound laboratory tech- niques and measurements needed by space scientists.}

for. And much of the research is just as useful on Earth as in outer space.

Knowing what to look for-and how-is JILA's speciality. Since the 1960's, national needs and priorities have changed somewhat and JILA has changed to meet those needs, but observing how gases radiate under different conditions, and deducing from that what's in them and what's going on, remains a fundamental part of JILA's work. The institute's work in atomic and molecular physics is recognized by scientists around the world.

\section{Cooperative Management}

Far from being a pyramid, the JILA organization chart more closely resembles New York's World Trade Center. Day-to-day management is handled by the 22 JILA "fellows," the permanent Ph.D. staff, headed by an elected chairman or -woman, much like a university department. By tradition, the chair alternates between NBS and CU employees and is changed every 2 years.

Above that level, it gets more complicated. Employees of NBS answer (with one exception) to Gebbie, chief of the NBS Quantum Physics Division, and through her to the NBS hierarchy. The one exception reports to the Bureau's Time and Frequency Division. CU employees answer variously to the university's departments of chemistry, physics, or astrophysical, planetary and atmospheric sciences. To complicate matters slightly, NBS fellows hold adjoint appointments in one of those three university departments.

All of this is to impress the point that it's amazing the institute works at all. In fact, it works very well. The single biggest advantage of the arrangement is the synergism created when two research institutions pool their resources, according to JILA staffers.

"JILA is unique in being a collaboration in which the government and the university participate as equal partners," observes Gebbie. "Everyone is very aware of the need to respect each other's prerogatives."

Dr. Carl Lineberger, a chemical physicist from $\mathrm{CU}$, is the current JILA chairman. "It is very difficult for a university, or an organization like NBS, to put together the critical mass of people in any single field that becomes a worldclass institution. You generally have to balance your resources across many different fields," he notes.

"In the fields represented at JILA, the university is much stronger than it could otherwise be," continues Lineberger. "There is absolutely no question that we do better in getting talented students and post-docs, and in attracting and retaining faculty, than 
we would do in the absence of JILA."

"Through JILA both NBS and $\mathrm{CU}$ enjoy a concentration of topflight researchers that neither institution could support on its own," Gebbie agrees.

One of the important contributions that NBS makes to the institute is the visiting fellows program, which each year brings in about 10 senior scientists from research institutions around the world to work at JILA-and there is a lot of competition for the positions.

From its participation in JILA, the Bureau gets enormous research "leverage." With a comparatively small division of only 19 people in all, NBS gets the benefits of the work of a much larger number of people. Counting grad students, post docs, visitors, and visiting fellows, there are 160 people in JILA, including 127 scientists.

The NBS members of JILA are unanimous on the advantages of the university atmosphere. "NBS is as healthy a federal lab as there is because of its good mixture of immediate and futuristic research, but you need constant exposure to new ideas. There is no other place besides a university where you have such a constant cross-current of high-level activity. In post-docs, we get applications from the best of the best," says Dr. John Hall, himself a world-known authority on lasers.

Dr. Gordon Dunn is an NBS physicist who has contributed several new techniques and instruments to the study of how ions interact with atomic and sub. atomic particles, processes that account for the behavior of much of the universe. One of the more recent accomplishments by his team-a way of measuring ionmolecule reactions at extremely low temperatures-has been called "the most important recent development" by a reviewer in the field.

Dunn credits much of this progress to the JILA atmosphere, observing, "The people l've worked with over the years-students, postdocs, and visiting fellows-have played major roles in all we've accomplished. My group now includes four students, a post-doc, and a visiting fellow, and they're all here for only a short period of time. There are a lot of personnel changes, so you get a constant influx of new ideas at a substantially reduced cost to the Bureau."

\section{Life in the Labs}

What does JILA study? Things that happen in gases on a molecular scale and precision measurements on a planetary scale.

Chemical physicist Dr. Stephen Leone, for example, has been

\section{"JILA is unique in being a collaboration in which the government and the uni- versity participate as equal partners," observes Gebbie.}

studying the ion chemistry of the aurora borealis, the northern lights. The issue was what sort of reactions are responsible for the aurora's rapid shifts of color from red to green.

Leone and his colleagues developed sensitive measurement techniques to isolate particular reactions that had long been suspect and to determine how much each reaction contributed to the phenomenon. The answers invalidated some widely held theories.

Who cares? Well, in addition to the acquisition of pure knowledge, the information is useful to the Air
Force because the same effects interfere with sensitive detection systems.

Leone, incidentally, is a good example of the return on investment NBS gets from JILA. On the Bureau's books, Leone is a single research scientist. When you count in his graduate students, post-docs and visiting scientists, Leone turns out to be leading a high-powered group of 16 researchers.

The typical JILA research topic sounds fairly arcane-work in its labs tends to be at the measurement frontiers of basic researchbut the applications are often quite practical.

For example, what are the energy characteristics of collisions between ions in highly excited states? How do those characteristics depend on the temperature and density of the gas?

The answers to those questions-which have required the invention of new measurement techniques-have immediate use in problems as diverse as studying the behavior of stars; designing new, more powerful lasers; understanding what is going on in experimental fusion energy systems; building highvoltage electrical generators and switches; and designing the most efficient street lights.

A great deal of JILA's work bears on the development and use of the laser. In the 1960's, the laser was an exotic device used for classroom demonstrations in physics. JILA researchers share in large part the responsibility for the laser's modern status as a precise instrument for measurement science.

JILA scientists have invented several new types of lasers, developed methods of measuring their performance, made some of the first fundamental discoveries on how to stablize the output of lasers, contributed basic research data

Continued on page 13 


\section{Gravity, When You Get Right Down to It .. .}

How much a pound weighs depends on mass and acceleration due to gravity. Mass is constant; the acceleration due to gravity changes, depending on how far you are from the center of the Earth, the density of the Earth under you, the planet's spin, and so forth.

JILA's Dr. James Faller has spent the last 2 decades studying gravity and ranks as one of the world's authorities in the field. One project has been the design and development of an extremely sensitive, portable instrument for measuring the local acceleration of gravity"little g."

To a degree, measuring the local gravitational acceleration is equivalent to measuring how far you are from the Earth's center at any given place. Working at accuracies in the neighborhood of 4 or 5 parts in a billion, Faller can detect changes in the distance to the center of the Earth to within 2 or 3 centimeters.

Why do we care about little g? "For one thing," says Faller, "little $\mathrm{g}$ is important to people who work with fundamental constants of nature. The value of the standard unit of electric current, the ampere, depends on little $\mathrm{g}$, and so do all of the other electric units that depend on the ampere."

Little $g$ affects the accuracy of basic units in mechanics, electricity, thermometry, and fluid dynamics, so standards laboratories are vitally interested in it.
Geologists and geophysicists are also interested, says Faller, because his instrument provides the equivalent of "a not-terriblyexpensive meter stick nailed to the center of the Earth." In earthquake-prone regions it provides an extremely accurate measure of how much the Earth's crust is moving.

Because little $g$ also depends on the density of the Earth, it's a useful tool in minerals exploration. Faller has already built one of his gravity meters for use by the Canadian Department of Mines, Minerals and Resources in prospecting.

Faller and his team of graduate students are also working on an imaginative new version of the classic Eötvös experiment, in which masses suspended from a torsion pendulum are used to test one of the fundamental principles of the general theory of relativity - that a feather and a lead balloon will fall at the same rate in a vacuum. In Faller's version, a float in a tank of purified water and an arrangement of electrostatic fields take the place of the traditional torsion pendulum.

Although the experiment is a classic piece of pure research, at the astonishing levels of accuracy reached in Faller's lab, the apparatus could have very practical applications. It is sensitive to nearby changes in mass, detecting, for example, the presence of a couple of additional bodies in the laboratory, or the departure of crowds

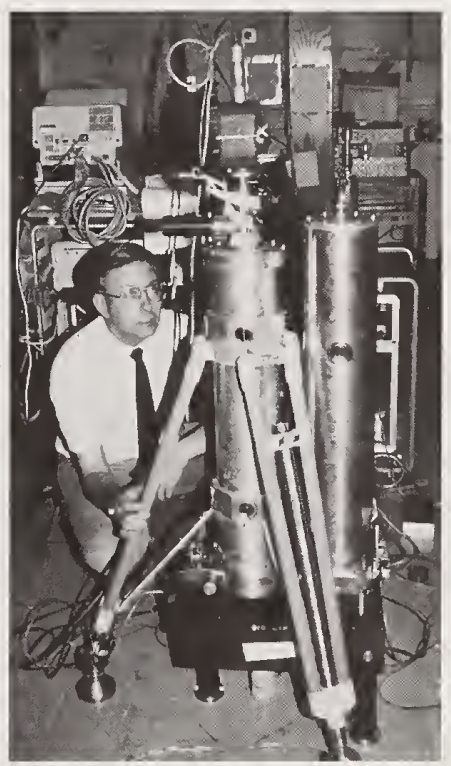

Dr. James Faller of NBS and the Joint Institute for Laboratory Astrophysics, with the JILA absolute gravity meter.

from a concert at the university stadium two blocks away.

One possible application, says

Faller, is in detecting the presence of tunnellers burrowing into bank vaults or nuclear weapon stockpiles. "The thing about security systems is that, in general, if you know what detectors are being used, you can shield yourself from them," says Faller. "Except gravity. It's very difficult to shield yourself from gravity." 


\section{The Light Fantastic}

That the laser has become an ubiquitous tool in laboratories around the world is in no small measure due to the efforts of $\mathrm{Dr}$. John Hall and his colleagues in Boulder.

Hall's interest in the laser began in the early 1960's, with experiments to measure the speed of light. The work required a very stable laser-one that produced light at a sharply defined frequency. They used the best, most stable laser available at the time, and it was none too good.

Hall and his colleagues at JILA and the NBS Time and Frequency Division turned their efforts to developing better techniques to stabilize lasers, tying the laser output to narrowly defined spectral lines in molecules like methane. "Over the course of 6 years," says Hall, "and over a succession of post-docs and visiting colleagues, we succeeded in improving the best laser resolutions from several million hertz to less than 1 thousand hertz." That work has continued up to today, producing some of the basic patents used worldwide to make stable research lasers.

Frequency-stabilized lasers made possible whole new areas of research. At JILA, they have been used for atomic spectroscopy at unprecedented levels of accuracy; to measure the relativistic dilation of time; in experiments on frequency and length standards that led the world's standards laboratories to change their definition of the meter; in one of the first successful experi-

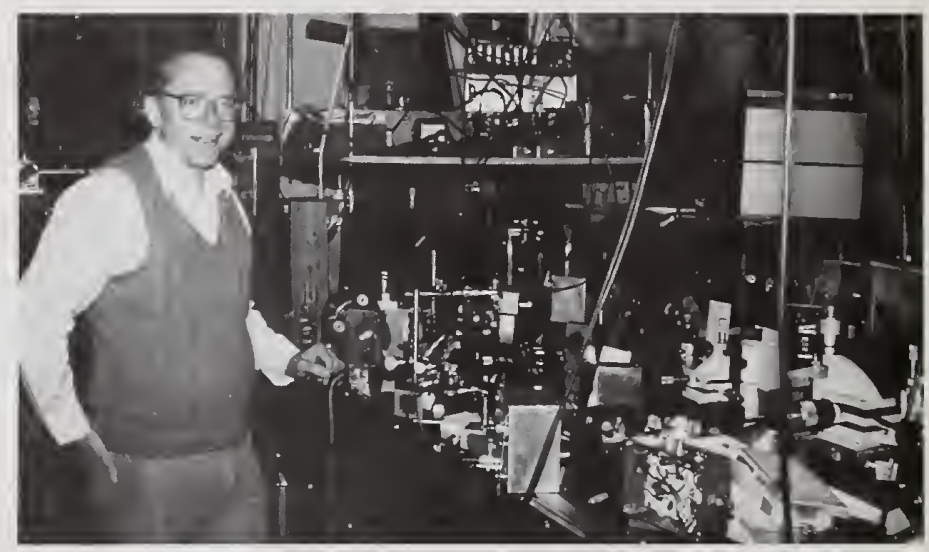

\section{Dr. John Hall of NBS and the Joint Institute for Laboratory Astrophysics with some of the apparatus used in his work on frequency-stabilized lasers.}

ments to produce a sample of neutral atoms "cooled" to a near-zero velocity (the other success was in another NBS lab); and hundreds of other applications.

Hall and his team continue to push at the limits of laser science. They are working with Bell Laboratories and with Stanford University on delicate measurements of atomic resonant frequencies. The latter collaboration has produced, as a by-product, a new laser stabilization technique.

One of Hall's most intriguing projects at the moment is a collaboration with the University of Texas on experiments to slip past the Heisenberg uncertainty principle, which sets absolute limits on the resolution at which quantum systems can be observed. The method being used is considerably different from the only successful experiment so far, which was conducted at Bell Laboratories.

Normally, explains Hall, you cannot measure the strength of an electromagnetic field such as a beam of light to better than within one photon, no matter how fine your apparatus. Even a field of zero-absolute darkcan only be measured to give-or-take a photon. Light, however, has two orthogonal components, and the uncertainty principle applies to the combination of the two components. In theory, says Hall, you can measure either component as accurately as you wish, so long as you are willing to let the other component "run wild.'

In practice, they are working on demonstrating a solid-state system in which, when the apparatus is turned on, the energy level of one component of light actually declines from the level measured in complete darkness. "A darkness which is darker than nothing," says Hall. "There are applications in the detection of gravity waves and a whole field of threshold signal detection. There'll be a lot of applications for a box that produces original darkness." 
needed for the design of lasers, and applied the laser to a bewildering array of measurement tasks from catching speeding atoms in mid-flight to measuring the distance to the moon.

The accurate measurement of great distances is another JILA specialty. Dr. Peter Bender, who calls himself a "theoretical experimentalist," is helping to improve the accuracy of distance measurements between radio astronomy centers in California, Massachusetts, and Sweden. At present, they can do it to within about 3 centimeters. Bender hopes to help improve that to 1 centimeter. The methodology is of great interest to geophysicists studying plate tectonics.

For several years, Bender has been working with Hall and Dr. James Faller also of JILA on longrange plans for an experiment using the world's largest measurement instrument ever-a laser interferometer using three satellites orbiting the Sun in a L-shaped formation with arms 1 million kilometers long. The interferometer would search for evidence of gravitational waves-a theoretically predicted but never observed phenomenon.

On the terrestrial plane, Dr. Judah Levine, who works with both JILA and the NBS Time and Frequency Division, has applied clever timing techniques to long-term experiments to measure minute shifts in the Earth's crust. "This might ultimately apply to earthquake prediction," explains Levine, "but that's in a very primitive state right now; there's no agreement even on what one should measure to predict earthquakes. We're still at the stage of trying to understand what's happening."

Levine's work at JILA has had an unexpected payoff for NBS: Some of the computer programs he developed for geophysical

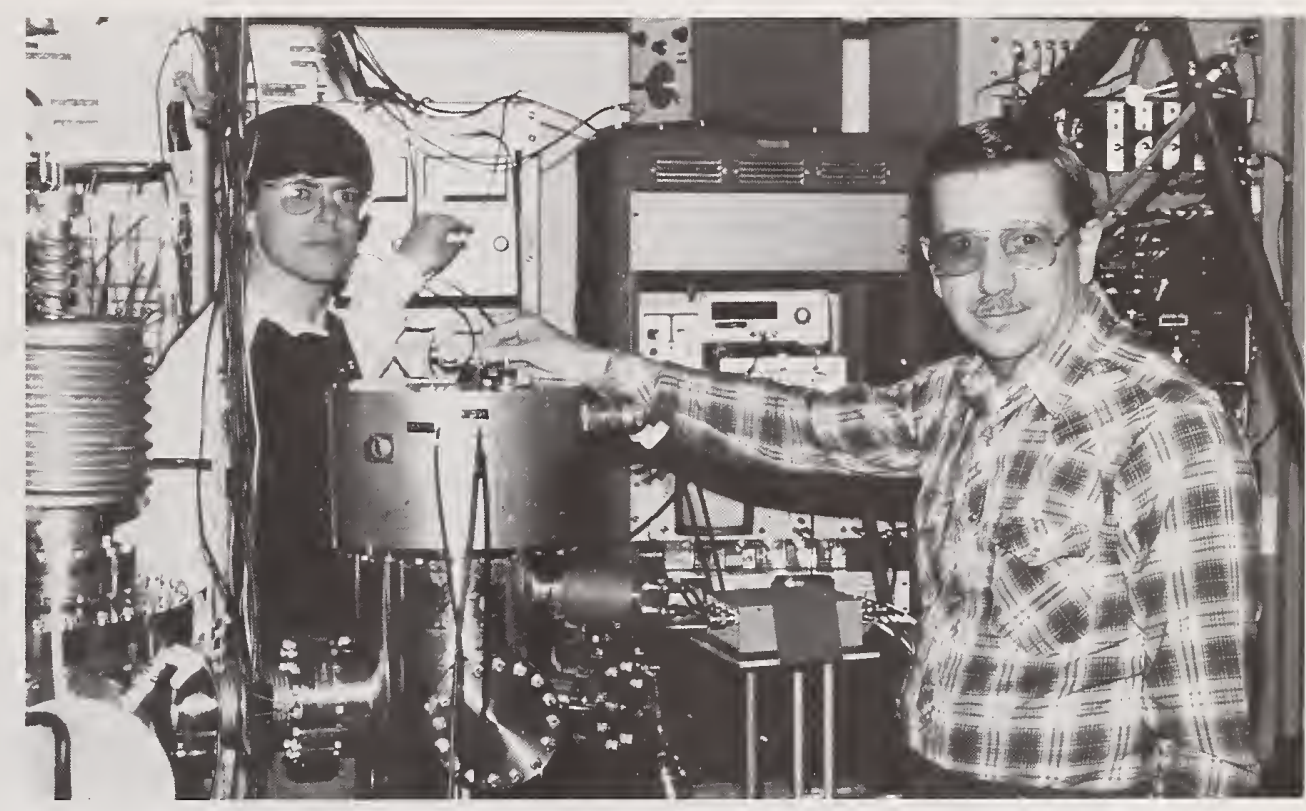

Dr. Gordon Dunn (right) of NBS and the Joint Institute for Laboratory Astrophysics and Brett DePaola, a post-doctoral research associate, with equipment used to study collisions of electrons and ions that occur in very hot plasmas.

measurements are now being used to maintain the NBS time scale, the national reference for time.

\section{"Concentration of Excellence"}

Perhaps the reason JILA works so well is that it manages to merge the characters of its two sponsors into a single institution.

The academic air of JILA and its close ties to the teaching program blend in well with the University of Colorado. The last CU program review panel cited JILA for the quality of its research and its productivity (JILA scientists publish over 200 papers a year, and the institute has graduated 130 Ph.D. students to date) and noted "there are only a handful of places anywhere that have a comparable concentration of excellence in the areas of laser physics and atomic and molecular physics."

Similarly, the institute's work at the frontiers of measurement technology fits in well with the goals of
NBS. Speaking of the complex array of research interests at JILA, gravitational researcher Faller observes, "The pedal notes in this fugue are the precision measurement techniques-pushing how well you can do measurements to the limits.'

There is an infectious energy about the JILA laboratories; staff members tend to talk about the "critical mass" of talents and interests that make up the institution. The general feeling is perhaps best summarized by Hall,

"When you find one guy who's 52 years old coming in at night to do research and another 62 coming in every morning at 7:30 to work in an exciting place to work."

by Michael Baum

NBS Public Affairs Specialist the labs, you know you've found 


\section{Safer, Quicker Ways to Prepare Samples for Chemical Analysis}

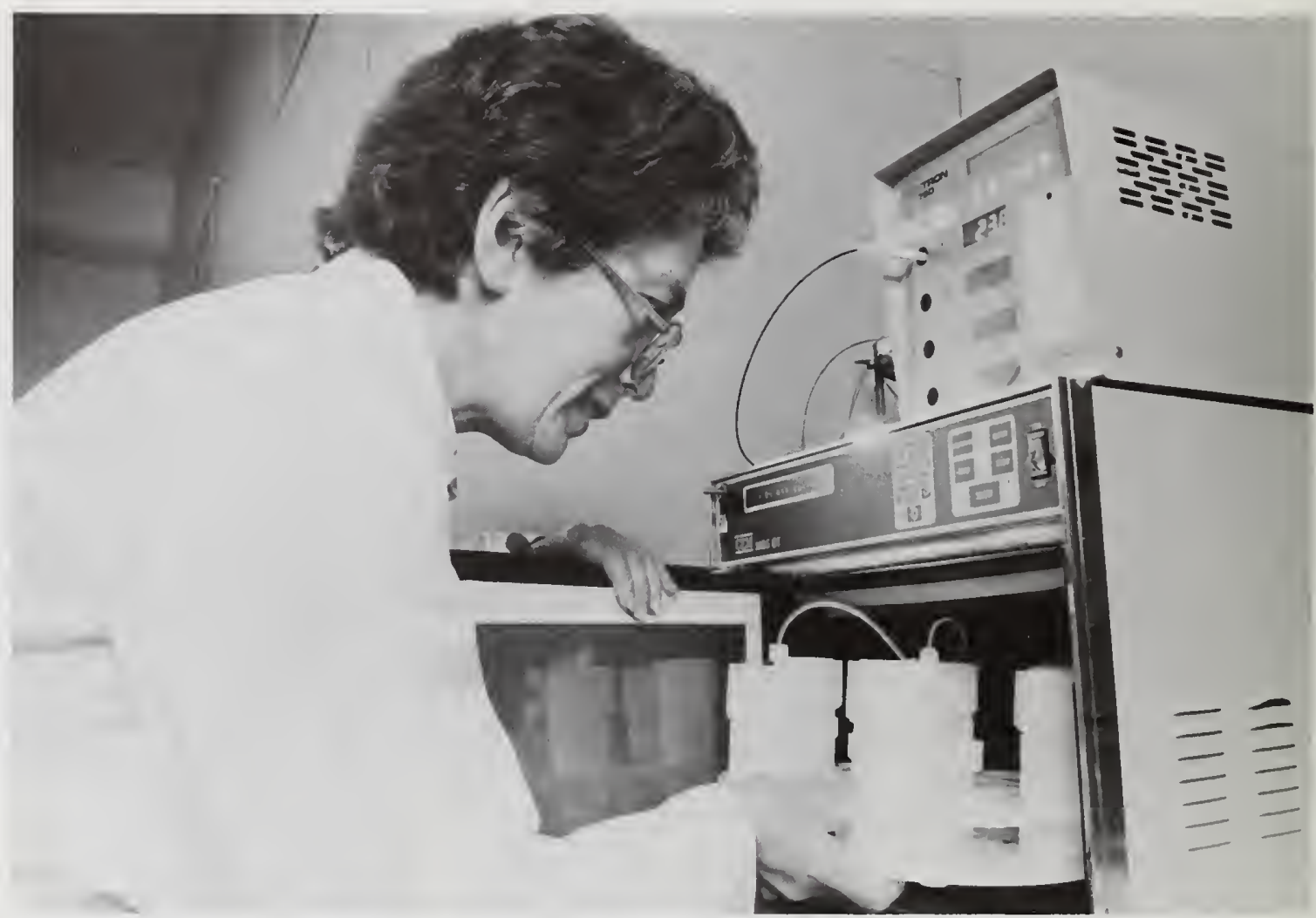

CEM Corporation chemist Lois B. Jassie places a carousel loaded with vessels into a research microwave oven. Specimens contained in the vessels will be dissolved and ready for analysis within 10 minutes.

$n$ an era when the word

"microwave" is tossed about liberally in reference to anything from kitchen ovens to backyard satellite dishes, microwave techology is also finding a market in a more specialized setting: the chemistry laboratory.

There oven-like microwave heating devices are gradually replacing "hot plate" methods of dissolving samples in acid for elemental analysis at trace levels (parts per million and lower). That's because for certain sample types, microwave technology is quick and contaminant-free, two factors essential to reliable chemical analyses.

While microwave techniques offer sweepıng improvements, there are still some "bugs" to be worked out to ensure their efficient operation and safety.

This is the goal of a joint research project between NBS and the Indian Trail, N.C.-based CEM Corporation, a maker of microwave equipment for research purposes. The organizations are refining techniques for rapidly dissolving samples-everything from biological specimens such as human bone and bovine livers to botanical, geological, metallic, and glassy samples-in closed vessels within a microwave chamber. Many industries using microwave methods have called NBS for help, and some, investigating dissolution and analysis procedures for materials such as nuclear waste and rock samples, have established long. term cooperative relationships with
NBS to better their understanding of the technique.

Ultimately, NBS and CEM aim to provide interested labs with a reliable procedure whereby chemists can select pre-determined conditions under which a sample can be rapidly and totally dissolved.

By combining the microwave technique's ability to quickly heat materials with the superior dissolving properties of closed containers under pressure, the NBS/CEM research team has devised a method of breaking down samples that takes less than 10 minutes. Traditionally, using hot plates and open-vented beakers, scientists could expect dissolving times of anywhere from 4 hours to 
4 days, depending on the com-

plexity of the sample.

"Clearly one of the best advantages of using microwaves is the speed," says Dr. Howard M. Kingston, an NBS chemist and manager of the joint project. "This is particularly important in the laboratory of today simply because the analytical instruments are now so fast, you need a quick way to dissolve samples just to keep pace with the analysis."

At NBS, scientists use custommade Teflon vessels with screw-on caps to contain the sample in nitric hydrochloric, and other acids. Vessel caps are outfitted with valves to relieve excess pressure, and the torque (tightness) of the caps is strictly controlled. This type of container is used to minimize contamination of the sample. Glass vessels, on the other hand, are not as contaminant-free. However, because they are used widely in industry and can withstand higher temperatures than Teflon, NBS and CEM plan to include glass vessels in their study.

Until the joint project began 21/2 years ago, there had been no systematic research to give scientists ideas about just what to expect from microwave dissolution. Research ovens were available, and scattered experiments had been done with them. But questions from industrial chemists lingered: How can you know what the temperature and pressure are in the vessel? What are the vessels' limitations? Can you ensure that microwave radiation is distributed equally? How can the vessels and the oven be vented safely?

Working with an early model of the presently used research oven, Kingston and his colleague, Lois $\mathrm{B}$. Jassie, a chemist for the CEM Corporation, set out to answer those questions

And while the going was not always easy, Kingston and Jassie now have a workable system complete with a database of information allowing industrial chemists to tailor their own microwave devices for desired results.

Their success has prompted the scientists to author technical papers about the microwave dissolution technique, and they are assembling a textbook on the subject to be published by the American Chemical Society. Kingston and Jassie also are taking advantage of well-attended gatherings of analytical chemists to spread the word about their research.

And the word is getting out. More than 200 companies, universities, and research laboratories have called NBS requesting help with specific applications of microwave techniques.

Kingston and Jassie say they welcome the calls, especially in light of the safety hazards which could arise if the technique is used improperly. Says Jassie,

"We have put a lot of emphasis on safety in our research, because you can imagine that with factors such

\section{...the NBS/CEM research team has devised a meth- od of breaking down samples that takes less than 10 minutes.}

as temperature and pressure involved, it is easy to get into trouble if you don't know exactly what you are doing."

The two scientists typically advise chemists of container pressure limits and equipment configurations to prevent uncontrolled venting of superheated acids. And their method of predicting temperature from microwave power has eliminated the need to guess about actual operating conditions.

Though requests for quick advice are common, some groups have established more formal, longer term relationships with NBS to study microwave dissolution. Some examples:
Los Alamos National Laboratory in New Mexico is investigating the effectiveness of microwaves in breaking down biological samples such as buffalo and human bone tissue. Scientists there have sought help at NBS in researching the elemental composition of bone tissue for anthropological studies of animal and human behavior

$\square$ Hints about the origins of early Earth crust are the goals of scientists at the Carnegie Institution of Washington, D.C., who are using microwave techniques to prepare samples of rocks older than $2 \frac{1}{2}$ billion years for isotopic analysis.

$\square$ E.I. du Pont de Nemours and Company scientists plan to use remotely controlled microwave equipment to dissolve and analyze radioactive sludge samples at the Defense Waste Processing Facility under construction at the Savannah River Plant in Aiken, S.C. Du Pont operates the plant for the Department of Energy.

Kingston and Jassie now are fine-tuning the techniques even further. For example, they are experimenting with a novel fiberoptic temperature-sensing system to monitor temperature more accurately and efficiently than the thermocouples they have been using. Also, they hope to improve the valve apparatus for the Teflon vessels and to test ways to automate the dissolution process.

Companies, universities, or government agencies interested in learning more about the NBS/CEM research should contact $\mathrm{Dr}$. Howard M. Kingston or Lois $B$. Jassie, A353 Chemistry Building, NBS, Gaithersburg, MD 20899, 301/921-3674.

by John Henkel

NBS Public Affairs Specialist 


\section{Researchers Study the Process to Improve Measurement Accuracy}

hy quibble about an error of onehalf percent or traces of an impurity present in concentrations as low as a few parts per billion? Isn't that nitpicking?

Hardly. And the chief of the NBS Chemical Process Metrology Division, Dr. Jaromir J. Ulbrecht, quickly illustrates how staggering the costs of imprecision can be. "Vast quantities of oil and natural gas are moved through pipelines in this country," Ulbrecht explains.

"Every half percent error in measurement means thousands or millions of dollars are lost." For natural gas alone, metering inaccuracies may be responsible for about $\$ 700$ million worth of gas being unaccounted for each year in this country.

Among the division's diverse clientele-chemical and related industries that range from aeronautics to utilities to winemaking - similar examples abound. For instance, Dr. James Whetstone, head of the division's process sensing group, refers to a measurement problem that has been a "constant point of contention between gas suppliers and semiconductor manufacturers.'

According to Whetstone, the manufacturers require high-purity gases to make microelectronic components, and suppliers of silanes and other gases aim to oblige their customers. Occasionally, however, water vapor, present in minute but damaging concentrations, contaminates a newly manufactured component. Did the impurity originate in the gas? as manufacturers often maintain. Or. as gas suppliers are likely to suggest, was the water vapor present in the plant?

Whetstone's group hopes to silence the argument by providing a standard method for measuring the water-vapor content of gases. Next fall the process sensing group will introduce a low-temperature "frost point generator" that can produce water vapor in concentrations as low as 20 to 30 parts per billion, according to Whetstone. An outgrowth of this development, he adds, are water-vapor concentration standards for high-purity gases, a boon to both semiconductor manufacturers and gas suppliers.

In a way, the four groups in the Chemical Process Metrology Division serve as arbiters for private companies and government agencies, including the Defense Department, Nuclear Regulatory Commission, National Aeronautics and Space Administration, and several others. As keeper and developer of the national standards for humidity, volume, liquid density fluid flow, and air speed, the division calibrates the reference instruments companies and government agencies use to measure these properties in the plant, laboratory, or field.

When agents from the Bureau of Alcohol, Tobacco, and Firearms, for example, inspect a shipment from the warehouse of an alcohol distiller, they use hydrometers that are calibrated against the liquid density standards maintained by the NBS process sensing group. The density measurement, which determines alcohol content, is the basis for calculating the federal excise tax on shipments of spirits.

"To continue to provide the best possible service, we've made major efforts to upgrade our calibration facilities and have introduced automation to improve efficiency and to reduce uncertainties in calibration," Ulbrecht explains.

\section{Back to Basics}

Reducing uncertainties in measurement is also the objective of the basic research under way in the division. Some of the studies will lead directly to new metering devices that can eliminate waste or improve efficiency, while providing a better understanding of how existing instruments work. Usually, there's more fundamental work to be done, however, like defining the poorly understood behavior of gases and liquids upstream and downstream from a meter in a pipeline or identifying surface properties of materials now used in sensing devices. The underlying reasoning is simple: If you understand the process better, you can improve measurement accuracy,

\section{"To continue to provide the best possible service, we've made major efforts to upgrade our calibration facilities and have intro- duced automation to im- prove efficiency and to reduce uncertainties in calibration," Ulbrecht explains.}

perhaps by perfecting the old instrument or by devising new approaches that, as Ulbrecht likes to say, yield "more robust instrumentation."

One candidate for improvement-solid-state sensing devices-has come under the atom-by-atom scrutiny of researchers in the process sensing group. These devices are actually miniature resistors, but when they come in contact with specific molecules, solid-state sensors adsorb some of the molecules and their resistance is changed in an electronic signaling circuit.

But for all their virtues, including simplicity and durability, current devices are less than ideal. "Solid state sensors for gas species are very nonspecific," Whetstone explains. "Take tin oxide. At 


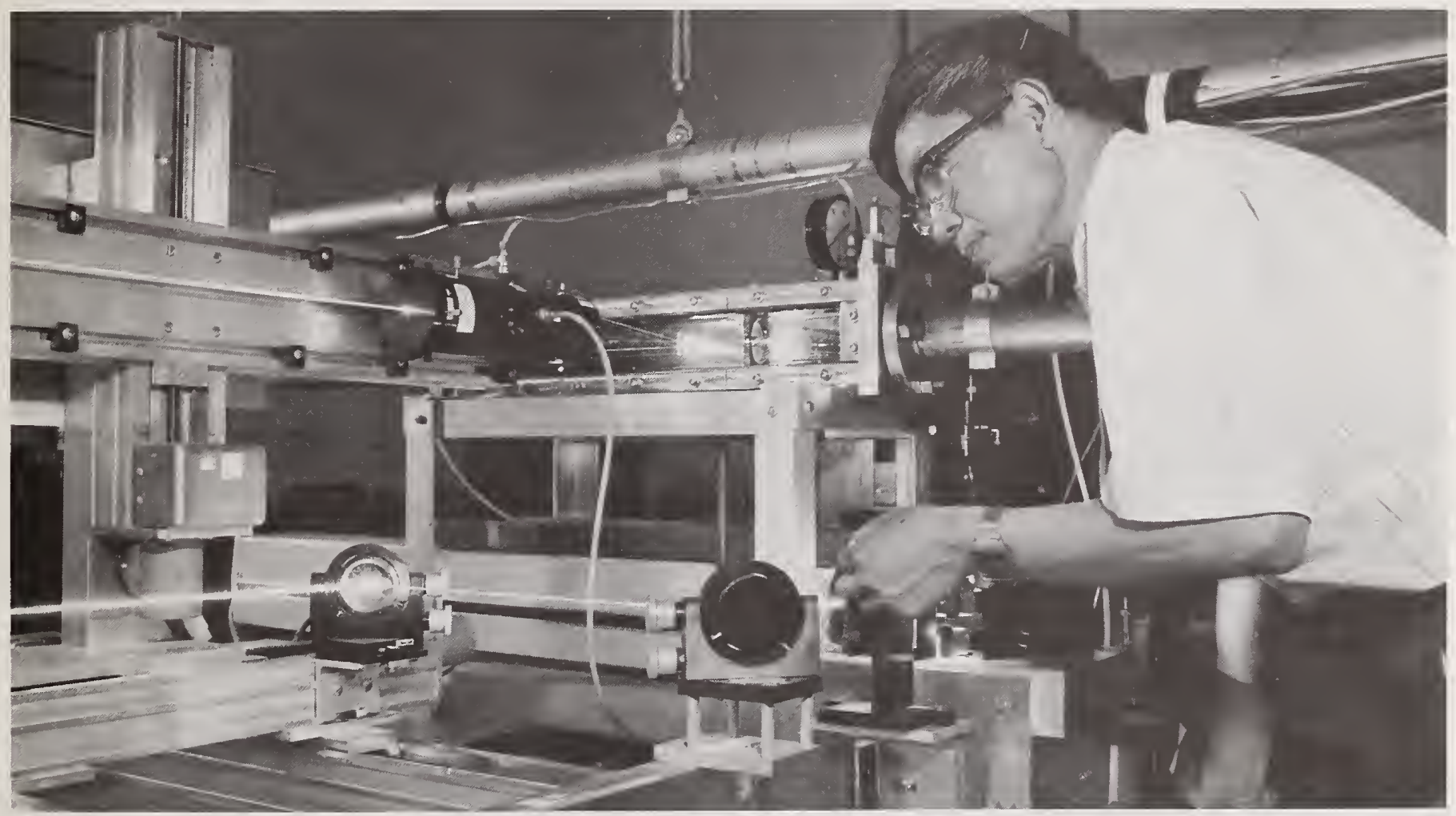

\section{Dr. Tsyh-Tyan Yeh is shown with the NBS laser Doppler velocimetry flow-metering research facility which is being used to study flow-measuring devices.}

elevated temperatures it absorbs an awful lot of stuff. You may be interested in the concentration of hydrogen atoms, but the sensor can't tell the difference between hydrogen and a hydrogencontaining gas like methane or hexane. So if you have a reaction stream that contains four or five constituents, you're fresh out of luck."

The explanation for the metal's indiscriminating ways lies on the surface, those first few layers of tin and oxygen atoms that are exposed to the surrounding atmosphere and often are arranged differently than the atoms that make up the bulk of the material. Greatly aided by two new facilities-one for creating films that are only a few angstroms (a few billionths of an inch) thick and the other for detailed surface analysis, the process sensing group has characterized surface adsorption properties of tin oxide. With this detailed information, the researchers can devise new approaches to improve the sensitivity of tin oxide sensors.

By strategically implanting palladium, platinum, and other catalysts on tin oxide surfaces, the researchers aim to build sensors that have much greater specificity than the conventional material. Whetstone says it's unlikely that the new sensors will "see" only one type of gas species, but they will be far more discriminating. The key, he says, is to learn the basic properties of catalyst-doped sensors, including their reactivity to different gases, and then use them in combination-as algorithmic or "smart" sensors.

A model of the sensors' properties can be translated into a computer program. On the basis of sensor and temperature measurements, the program can be used to "deconvolute" the information, Whetstone says, and deduce concentrations of various gases in a chemical reactor, for example. "Whether the measurements can be made in real time will depend on how fast the program is,"

Whetstone says "It's a complex modeling job. That's why we're enlisting the help of the University of Maryland's Center for Systems 


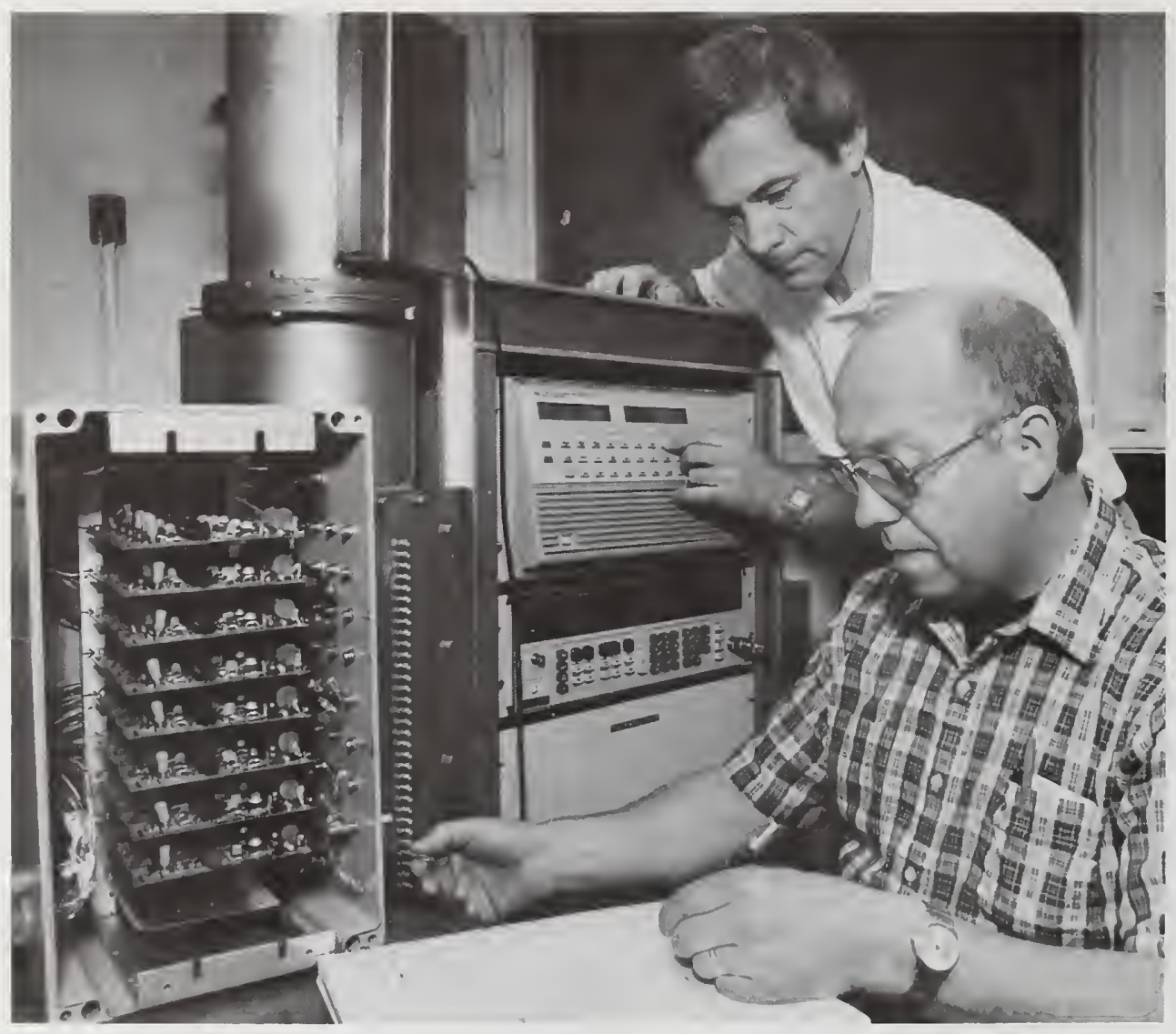

\section{Dr. Adolfas Gaigalas (standing) and John Houser review test results of a nonintrusive metering system used to measure the solids in a pulp slurry pipeline.}

Engineering to work on the modeling and computations."

Despite the complexity of the task, Whetstone predicts that the future in process sensing lies with the tandem of multiple sensors and algorithmic programs. That's why his group has mounted a parallel effort for sensing concentrations of specific molecules in liquid streams, a development that would benefit food processors, biotechnology and chemical-engineering firms, and a host of other companies. Tailored sensors also interest the Nuclear Regulatory Commission (NRC). The NRC commissioned Dr. Ken Kreider of the processing sensing group to study the feasibility of nuclear waste containment.

Focusing on iridium oxide and beginning with a detailed study of the metal's surface properties, the group plans to evaluate the possibility of using ion-specific sensors encapsulated in selectively permeable polymer membranes.

Besides gains in specificity, such sensors would offer much greater durability than the glass-encased sensors now used. "They won't break and go down the process line," Whetstone says. Conceivably, solid-state sensors could be placed in food products as a check on spoilage or processing conditions. using the devices as monitors of
In contrast, glass devices can't be used for this purpose because of the danger of breakage

\section{Longer Life for Sensors and Meters}

The importance of durability can't be underestimated, according to division chief Ulbrecht. "Many meters must operate in harsh, corrosive environments, such as slurries and effluent streams," he says. "If a meter is sensitive to slight changes caused by erosion, you've got problems. Once a meter has eroded, you can forget it. Your measurements will be inaccurate.'

The consequences of inaccuracies are waste and inefficiency. "Chemical reactions take place in fixed proportions," Ulbrecht explains. "If your measurements of streams entering a continuous flow reactor are off by a few percent, you may not get the right chemical reaction or you may get only a fraction of the desired product."

For paper manufacturers, errors in measurement of the solids in a pulp slurry pipeline, an especially corrosive environment, translate into an inferior product. Currently, the standard meters used to measure the solids fraction are inserted directly into the pipeline, where they inevitably break down.

Dr. Adolfas K. Gaigalas, head of the multiphase reacting flows group, has come up with a novel technique to avoid this problem and, in the process, improve the quality of measurement. The device he invented is protected from the corrosive effects of the slurry and provides real-time measurement of the solids fraction.

In a project funded by the Department of Energy's Office for Industrial Programs, Gaigalas devised a nonintrusive metering system that exploits the properties 
of radio waves. Flat, thin radiowave antennas are built directly into the inside wall of the slurry pipeline. Between the two antennas and also imbedded into the pipe wall is a sophisticated detector that samples a radio wave-caused electrical field at 32 separate points.

According to Gaigalas, the final measurement-the determination of the slurry's solids content-is derived from a three-step procedure. First, one antenna fires, and then the second. In the third step, both antennas fire simultaneously, creating an interference pattern beneath the detector. At each step, the detector records the resulting electromagnetic field and transmits the information to a computer that calculates the speed of the radio waves in the slurry. The calculations are compared with a mixing model, and the comparison yields an accurate measurement of the solids

\section{If you understand the pro- cess better, you can im- prove measurement accuracy, perhaps by per- fecting the old instrument or by devising new approaches...}

content. The entire procedure takes about a minute, considerably faster than current methods.

A prototype of the sophisticated meter already has been tested at the Institute for Paper Chemistry in Appleton, Wisc. The next stepbuilding full-scale models for testing in actual paper mills-will soon follow. Meters are scheduled to be tested in two plants, one owned by the Bowater Southern Paper Company and the other by the Weyerhaeuser Company. Gaigalas says he is grateful for the industry's cooperation, but adds that paper manufacturers have an incentive. "They are eager to get a meter that's accurate," he says.

"It's one thing to test a device in the controlled environment of the laboratory and another to do it in a manufacturing plant," Gaigalas says. "I'm very optimistic, though. I think it will work, and I don't think we'll encounter any problems."

\section{Working Together}

Another gauge of the widely shared desire for accurate meters is the participation of industry in two consortia recently started by $\mathrm{Dr}$. George E. Mattingly, head of the fluid flow group. One consortium, which is studying the measurement problems that result when a meter is installed too close to a pipe "elbow" or valve, counts 10 firms as members, in addition to the Department of Energy. The other consortium has a roster that includes nine companies and NASA, all of which are interested in improving the performance of vortex-shedding flow meters. These devices, which are used in a wide variety of situations, determine flow rate by detecting the eddy-shaped vortexes created by liquid flowing through the meter.

"Flow-measuring devices have been around for decades, but there still is a certain amount of mystery about what really goes on when fluid is flowing through a flow meter," Mattingly explains. "Our goal is to combine the measurement expertise and fluid research facilities at NBS with the industrial needs of consortia members."

Essential to the two groups' efforts is the NBS laser Doppler velocimetry (LDV) flow-metering research facility. This new facility will allow researchers to measure fluid conditions characteristic of those confronted in the plants of participating firms.

Although research will be tailored to the problems of consortia members, Mattingly stresses that the emphasis will be on learning the basic flow characteristics of liquids and gases. "This understanding is required to properly upgrade fluidmetering standards, which is the most practical way to achieve accurate flow-rate measurements," he says.

Lasers also play prominent roles in the varied work of the Chemical Process Metrology Division's largest unit, the high-temperature reacting flows group. The group, headed by Dr. Hratch G. Semerjian, has demonstrated the analytical strength and diversity of the combination of lasers, fiber optics, and computers.

Just as certain aspects of the behavior of gases and liquids in pipelines are regarded as a "black box," combustion processes pose troubling unknowns that can't be addressed with current analytical techniques. The combustion of gases in industrial boilers, for example, is examined after the fact, by analyzing emissions rising through the "smoke stack." The optimal approach-one pursued by Semerjian's group-would be to monitor fuel-burning as it happens

The optical diagnostic technique the group has developed is akin to the CAT (computerized axial tomography) scanning methods used for diagnostic imaging in medicine. As in CAT scanning, the group's tomographic method produces computerized images that are composites of many projections, each taken from a different angle. But instead of using $x$ rays to create the richly detailed, three-dimensional images, the NBS researchers use tunable lasers to generate a wealth of information about the light-absorbing and -scattering properties of molecules and particles in the flame. As six laser beams scan the field, the attenuated light from each beam is picked up by a photodetector and 
then sent to a photoamplifier, which intensifies the signatures. In the last leg of this relay of signals, the photoamplifier transfers the spectroscopic data to a computer, which processes information gathered from six different angles and produces the composite image.

From the image, the creation of a complex computer program, researchers can determine the temperature of the flame, the composition and concentration of the molecular components in a fuel, and the make up, concentration, and movement of combustion products. In all, the image provides a detailed and regularly updated accounting of what happens during combustion.

While this detailed information will aid efforts to improve fuel efficiency and to control emissions, Ulbrecht foresees other applications for laser tomography. "A natural outgrowth," he says, is studies of "chemical vapor deposition," the process used to manufacture silicon wafers and fiber-optic materials. For all the technological marvels it underlies, the process, which can be used in different ways, is inefficient. Ulbrecht roughly estimates that silicon-chip manufacturers discard up to 60 percent of the chips they make.

"Before you can control the process, you must understand the chemistry and the kinetics of the process," Ulbrecht says, adding that laser tomography could subject chemical vapor deposition to the scientific scrutiny desired.

The considerable powers of optical diagnostics also are being directed toward many other uses, including analysis of the incineration of hazardous wastes, a problem that is being studied by other groups as well. Burning of hazardous materials is a potential solution to the dilemma posed by the growing accumulation of potentially toxic wastes at dump sites. But, as Ulbrecht points out, incineration must be strictly controlled, which means that accurate measurements are essential. Otherwise, the process might create new pollutants that go undetected and are emitted into the atmosphere, Ulbrecht explains.

\section{Looking to the Future}

Biotechnology firms are among the intended beneficiaries of other ongoing research in the division. These firms are expected to become a major force in the chemical-processing industry. Says NBS researcher Dr. Baldwin Robertson, a member of the multiphase reacting flows group, "Bioprocessing is the chemical

\section{"This understanding is required to properly upgrade fluid-metering standards, which is the most practical way to achieve accurate flow-rate measurements."}

engineering of the future,' replacing the petroleum-based processes that have characterized the industry for decades.

Bioprocessing, which exploits biochemical reactions, also presents special measurement needs. Robertson is addressing one of these needs in his studies of the destructive force created by stirring the nutrient-rich broth in a fermentation vat. While mixing is a common feature of chemicalmanufacturing processes, it is especially critical in processes that use living cells. In the past trial-and-error approaches to find the optimal stirring rate for a reaction were adequate, but these approaches won't do for biochemi cal reactions, Robertson explains.
"Vigorous stirring is necessary to get oxygen to the cells in the broth," Robertson says, but too intensive stirring can damage the cells or limit their growth.

With collaborators from the University of Pierre and Marie Curie in Paris, Robertson has devised an electrochemical method for measuring the rate of "shear strain," the deformation that results when liquid slides across a mixing blade Robertson stresses that his work is at the basic research level, several steps removed from actual use in an industrial process. But the ability to measure a key variable in many manufacturing processes, not just fermentation, strengthens the scientific foundation from which gains in efficiency and productivity ultimately emerge.

While Robertson's work focuses on a factor that influences cell growth and survival in a fermentation vat, researchers in another group are developing a method for monitoring the biochemical reactions that take place in the vat. The technique, called laserinduced fluorescence, produces a wealth of data for determining the types of concentrations of intermediate compounds formed during the biochemical reactions. (See the article on page 24.)

In cooperation with the Lehigh University Center for Biotechnology Research, the NBS researchers aim to unite their diagnostic system with computerized models, a combination that will allow continuous surveillance of the fermentation process.

In all of these projects, the researchers' overriding goal is to help the chemical-processing industry improve measurements, and thus efficiency and economy, by providing ever better measurement methods.

by Mark Bello Washington, D.C.-area Science Writer 


\section{Expanded Version of IGES Standard Available}

he National Bureau of Standards has released a new, extended version of the popular Initial Graphics Exchange Specification (IGES), a standard data format designed to simplify the exchange of computer-generated design information between otherwise incompatible computer-aided design (CAD) systems.

The updated specification, Version 3.0, contains expanded capabilities for representing part geometries, new capabilities to allow for creating standard "libraries" of parts, and a new method of reducing the size of IGES files. The new version also includes many clarifications and refinements to the IGES standard based on experience with using an earlier version of IGES across a wide variety of CAD systems.

The original IGES was developed in 1979 under sponsorship of the

\section{Version 3.0 contains ex- panded capabilities for representing part geom- etries, new capabilities to allow for creating stan- dard "libraries" of parts, and a new method of re- ducing the size of IGES files.}

Air Force Integrated ComputerAided Manufacturing Program. The specification defines a computer file format for the storage of threedimensional geometric information and two-dimensional drawing information that is created by CAD systems.

Data can be exchanged between two otherwise incompatible CAD systems by using pre- and postprocessors to translate the data out of the first CAD system into the IGES format, and out of the IGES format into the second system.

Department of Defense and National Aeronautics and Space Administration procurement specifications routinely require the use of IGES, and IGES translators are available as options from every major U.S. CAD-system manufacturer

IGES is managed by a joint industry-government group coordinated by NBS. The first version of IGES was adopted by the American National Standards Institute (ANSI) as a major portion of its standard Y14.26M. Version 3.0 was submitted to ANSI in March 1986.

In addition to clarifying several aspects of earlier versions of the standards, IGES Version 3 adds new capabilities in geometry for offset curves, offset surfaces, and curves on a parametric surface. A trimmed surface entity allows for the definition of surface boundaries, and new capabilities in annotation have been added.

IGES 3 introduces greatly enhanced capability for user-defined MACROS essential for creating standard part libraries of symbols and components.

IGES 3 also introduces a method of reducing IGES files to one-third of their previous size, using a compressed ASCll format, to save on storage space and telecommunications costs.

While continuing to upgrade and improve the graphics exchange standard, the IGES organization has also begun work on a Product Data Exchange Specification (PDES), which will allow a complete product model database to be exchanged and used directly by
IGES is a standard data format designed to simplify the exchange of computer-generated design information between otherwise incompatible CAD systems.

advanced computer-integrated manufacturing programs such as automatic process-planning or inspection systems.

Information such as manufacturing features, tolerance specifications, material properties, and surface finish specifications will be made available to application programs in the PDES format.

IGES technical meetings are held regularly throughout the year to discuss enhancements and modifications to the IGES standard. The next meeting is scheduled for the week of October 20,1986, in Huntsville, Ala. Interested persons are invited to contact Gaylen Rinaudot, IGES coordinator, A353 Metrology Building, NBS,

Gaithersburg, MD, 20899, 301/921. 3691.

The Initial Graphics Exchange Specification (IGES), Version 3.0 (NBSIR 86-3359) is available for $\$ 40.95$, prepaid, through the National Technical Information Service, Springfield, VA 22161 Order by PB \#86-199759. Microfiche copies also are available. M.B. 


\section{NBS Studying New Technique to Identify Irradiated Foods}

esearchers at the National Bureau of Standards are experimenting with an extremely sensitive analytical procedure that may make it possible to determine whether or not a sample of meat has received radiation processing to sterilize it or to inhibit decay

At present, no reliable test method exists for determining whether or not a foodstuff, other than dried spices, has been treated with ionizing radiation.

The technique may be adaptable to vegetable matter and seafood as well as meats, according to Drs. Michael Simic, Miral Dizdaroglu, and Lisa Karam of the NBS Center for Radiation Research. In addition, efforts are under way, in collaboration with the NBS Center for Analytical Chemistry, to develop a scale to determine how much radiation was administered to the foodstuff.

Radiation processing of foods, especially meats, is a comparatively new procedure in the United States, although it is practiced widely in some other countries. Doses of ionizing radiation-either $x$ rays or electron beams produced by machines, or gamma rays produced by radioactive substances-can extend the shelf life of iruits, vegetables, and meats by retarding spoilage. At sufficiently high levels, radiation will either kill harmful bacteria or insects in the food or inhibit their reproduction. Fresh meat, for example, can be sterilized and stored in air-tight packages at room temperature for months or years. The food itself does not become radioactive.

In the 1960's, the Food and Drug Administration (FDA), which regulates food irradiation, approved the use of radiation for treating potatoes and wheat, although the process is not used commercially in the United States. In 1983, the irradiation of spices to kill insects was approved. In the past year, final approval was granted for low-level irradiation of pork to kill trichinae worms and of fruits and vegetables to extend shelf life.

The total dose of radiation given to foods must be carefully controlled. A dose that is too low fails to produce the desired effect, while a dose that is too high may damage the food. In addition, the FDA sets maximum exposure limits for the lifetime of the food product. In the case of pork, for example, the

\section{Experiments at NBS demonstrate that the amount of orthotyrosine in the fiber of chicken meat increases in direct proportion to the amount of radiation the meat has received.}

limit is 100 kilorads. While just 1 kilorad is sufficient to kill a healthy, adult human, less complicated organisms like insects are hardier.)

These limits present a problem for regulators and food importers, who may need to determine whether a given shipment has ever been irradiated, and if so, to what extent.

"What you are looking for is a reliable, built-in 'dosimeter' in foods," explains Simic, the NBS project chief. "For example, the Germans have developed a method, based on fluorescence, to tell whether or not spices have been irradiated. It has two problems, though. The spices have to be dry, very dry, and the test can't be repeated-the effect fades after the first time."

The NBS effort at first concentrated on finding so-called "unique radiolytic products" - chemicals produced by the effects of radiation that would not be present in unirradiated food. The amounts of such chemicals produced by radiation processing would be very small-perhaps a few micrograms in every gram-but ideally the amount present should increase in direct proportion to the radiation dose received, a built-in dosimeter.

The researchers used a specialized analytic technique-gas chromatography/mass spectrometry with selected ion monitoring-in their search for a useful "dosimeter" chemical.

"This is a very sensitive technique. You can detect quantities as small as a few picograms (1 picogram $=0.000000000001$ gram)" says Dizdaroglu, "but you have to know what you're looking for. We studied the radiation chemistry of peptides and proteins in model systems and made chemical kinetics measurements to determine what the likely reactions were, and what the products would be."

An early candidate was the amino acid ortho-tyrosine, which is produced by the addition of a hydroxyl (hydrogen-oxygen) radical to another amino acid phenylalanine. Hydroxyl radicals are formed by the break-up of water molecules under ionizing radiation. Ortho-tyrosine is a chemical isomer of a naturally occurring amino acid, paratyrosine (that is, both have the same chemical formula, but they differ in the location of the hydroxyl group.)

The researchers ran into a snag when they discovered that unirradiated control samples of chicken meat also contained minute traces of ortho-tyrosine. "Apparently," says Simic, "the enzyme in the body that is supposed to make para-tyrosine out of phenylalanine occasionally makes a mistake."

The concentration was so low that it had escaped the notice of food researchers, but it was high enough to interfere with the delicate test procedure the NBS team was trying to develop.

A suggestion from a colleague at the Department of Agriculture led to the solution. "The idea is that 
amino acids are not necessarily used at the same place where they're made," according to NBS' Karam. "Meat has two basic components, fiber and everything else-a kind of watery fluid. Tyrosine is made from phenylalanine in the fluid, and then the body takes it and attaches it to the fiber. Ortho-tyrosine can be made by mistake sometimes, but the body appears to recognize it as a mistake and won't use it in the fiber."

The answer, then, was to carefully wash meat specimens in water to remove everything but the fiber. Any ortho-tyrosine found in the washed sample could only come from the radiation-induced transformation of phenylalanine already present in the fiber.

Experiments at NBS demonstrate that the amount of ortho-tyrosine in the fiber of chicken meat increases in direct proportion to the amount of radiation the meat has received. The concentrations are at the level of a few parts per million. Unirradiated control samples show no ortho-tyrosine in the fibrous tissue at the current limits of detection.

"The great thing," notes Simic, "is that we are not talking about some chemical that is created uniquely in food that has been irradiated. Ortho-tyrosine occurs naturally in quantities much greater than are created by radiation processing, and yet in the meat fiber it is apparently produced only by irradiation, so you can use it as a natural dosimeter."

NBS is continuing to study this new technique with the goal of developing an analytical method for determining irradiation-dose levels in meats. The Bureau will also investigate its applicability to other foods. The U.S. Department of Agriculture is supporting the application of this basic research to the measurement of radiation dose in poultry and pork. Technical advice is also being provided by the Food and Drug Administration. M.B.

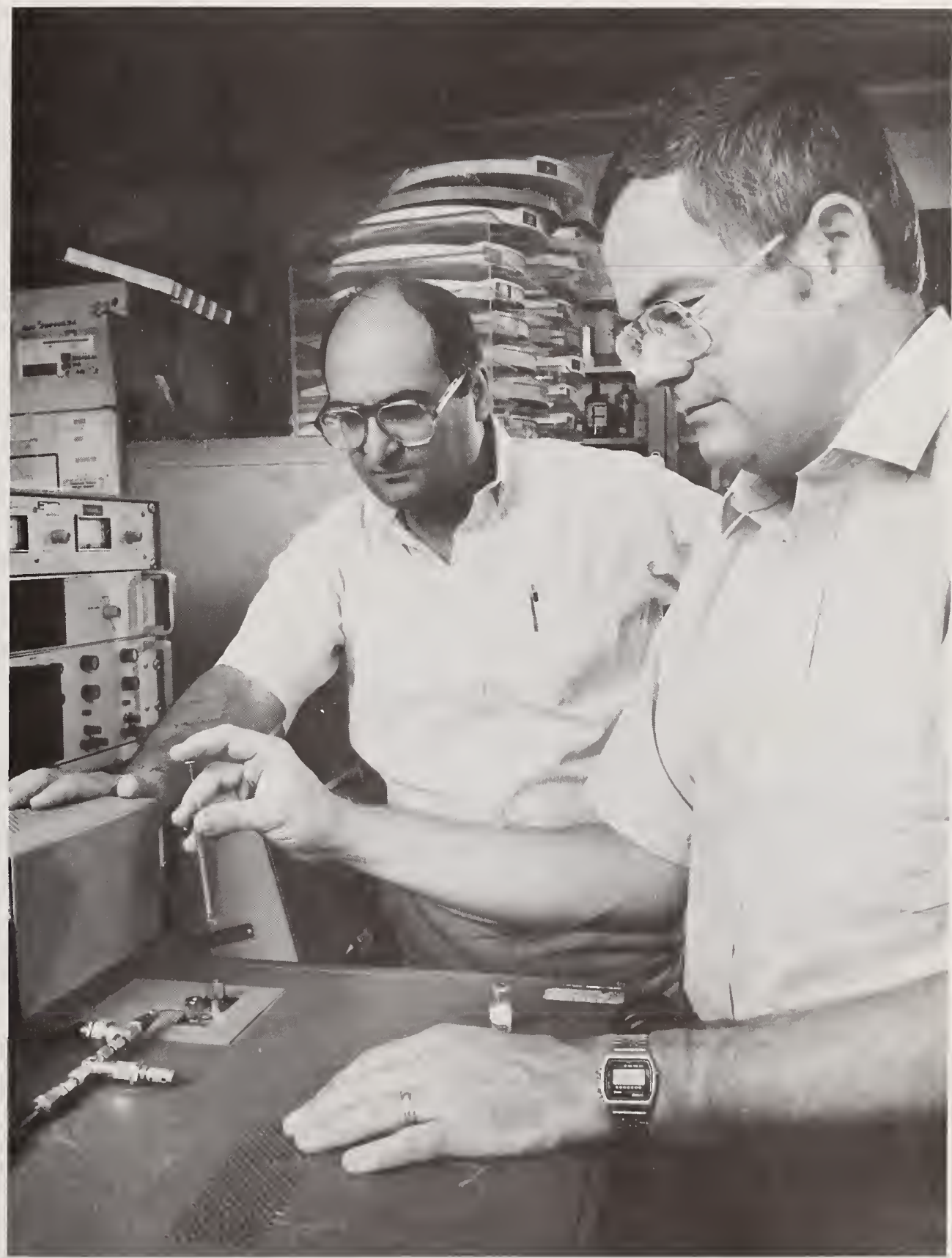

Dr. Miral Dizdaroglu (left) of the NBS Center for Radiation Research and Dr. Michael Welch of the Center for Analytical Chemistry prepare to inject a sample of meat fiber into a combined gas chromatograph/mass spectrum analyzer. Sensitive analytical procedures developed at NBS may soon make it possible to determine whether or not common foods have ever received doses of radiation-and if so, how much. 


\section{NBS Research in Biotechnology: Providing the Scientific Fundamentals}

he harnessing of bacteria to generate insulin and the capture of enzymes to speed fermentation of soy sauce are just two feats of biotechnology-a growing field whose products are expected to gross over $\$ 50$ billion by the year 2000 . The potential of biotechnology research is great: a cleaner environment, improved diagnosis and treatment of diseases, better food crops, and alternative energy sources. But like most fledgling industries, biotechnology is in need of standards and firm scientific fundamentals to assure better control and efficiency of its commercial processes.

As it has for many other new industries-from cast iron foundries in the early 1900's to the semiconductor manufacturers of today - the National Bureau of Standards plans to help the biotechnology industry by providing essential measurement methods, standard data and materials, and scientific fundamentals. For example, researchers at the NBS Center for Analytical Chemistry $(\mathrm{CAC})$ are refining innovative analytical techniques so that minute, yet potentially harmful, impurities in protein biotechnology products such as insulin or growth hormones can be detected. They are also developing state-of-the-art biosensors that can speed the clinical diagnoses of various disorders and aid the manufacture of genetically engineered microbial products.

Other researchers within the Bureau's Center for Chemical Engineering (CCE) are working to improve the efficiency of biochemical reactors as well as develop techniques for separating biochemical products from solutions. At the same time, investigators at the NBS Center for Chemical Physics (CCP) are uncovering the detailed structure and functional relationships of enzymes that are frequently used to generate biochemical products. CCP researchers also are identifying how various factors such as temperature and $\mathrm{pH}$ influence the functioning of enzymes. In addition, NBS has joined the University of Maryland and Montgomery County Md., in establishing a Center for Advanced Research in Biotechnology. (See page 6.)

"Biotechnology is a whole different ball game compared to the tech nologies most industries are used to," says NBS biochemist Dr. Ann Plant. "We don't have a lot of the basic science at our disposal that will enable us to take microbes, enzymes, and so forth out of biological systems and apply them immediately in an industrial setting."

A major challenge facing biotechnology companies is scaling up the laboratory production of genetically engineered microbes to generate commercially feasible quantities of products. To accomplish this effectively, manufacturers must be able to monitor quickly and precisely a number of environmental factors, such as nutrient levels, and the concentrations of desired and waste products within reactors so

\section{The advantage of this biosensor...is that it is quick and requires a minimum of equipment and expense.}

adjustments to improve quality and productivity can be made quickly.

Plant and her coworkers are developing a biosensor that recognizes specific organic molecules and uses them to produce measurable electrical signals. The biosensor employs the body's own natural detectors-antibodieswhose chemical arms latch onto specific compounds called antigens within their midst. Plant and her colleagues have taken these antıbody arms, attached them to beads, and added a solution of lipid vesicles (similar to water-filled balloons) containing electrochemical or fluorescent markers. The vesicles have on their surfaces the antigens of the compound of interest-insulin, for example-and consequently bind to the antibodies on the beads Then when a solution containing insulin is added, the insulin molecules displace the vesicles which return into solution and are collected. When detergent is added to the solution containing the vesicles, they explode, releasing the electrochemical or fluorescent markers. This allows the number of insulin molecules displacing the lipid vesicles to be determined.

The advantage of this biosensor over other techniques currently used to measure small quantities of biological compounds is that it is quick and requires a minimum of equipment and expense. Using this system it is possible to do an analysis for a compound in only 10 minutes whereas an analysis for the same compound using other standard techniques such as radioimmunoassay could take hours or even days

Besides being used as a monitor in biochemical reactors, Plant also expects this biosensor system to be useful in a clinical setting. The sensor can monitor the blood levels of drugs such as digoxin, for example, that can be lethal at levels only a small fraction above the levels at which they are effective. "The system could be set up in a physician's office and the tests could be performed while the patient waits," Plant says.

NBS scientist Dr. Hratch Semerjian is also working on monitoring techniques for biochemical reactors. He hopes to fingerprint the identity and quantity of compounds within a reactor by shining a laser beam into the reactor and noting how much light is absorbed and the pattern of wavelengths of light reemitted. Each compound will reemit light in a distinctive wavelength pattern, Semerjian explains, and the quantity of light emitted will indicate a 


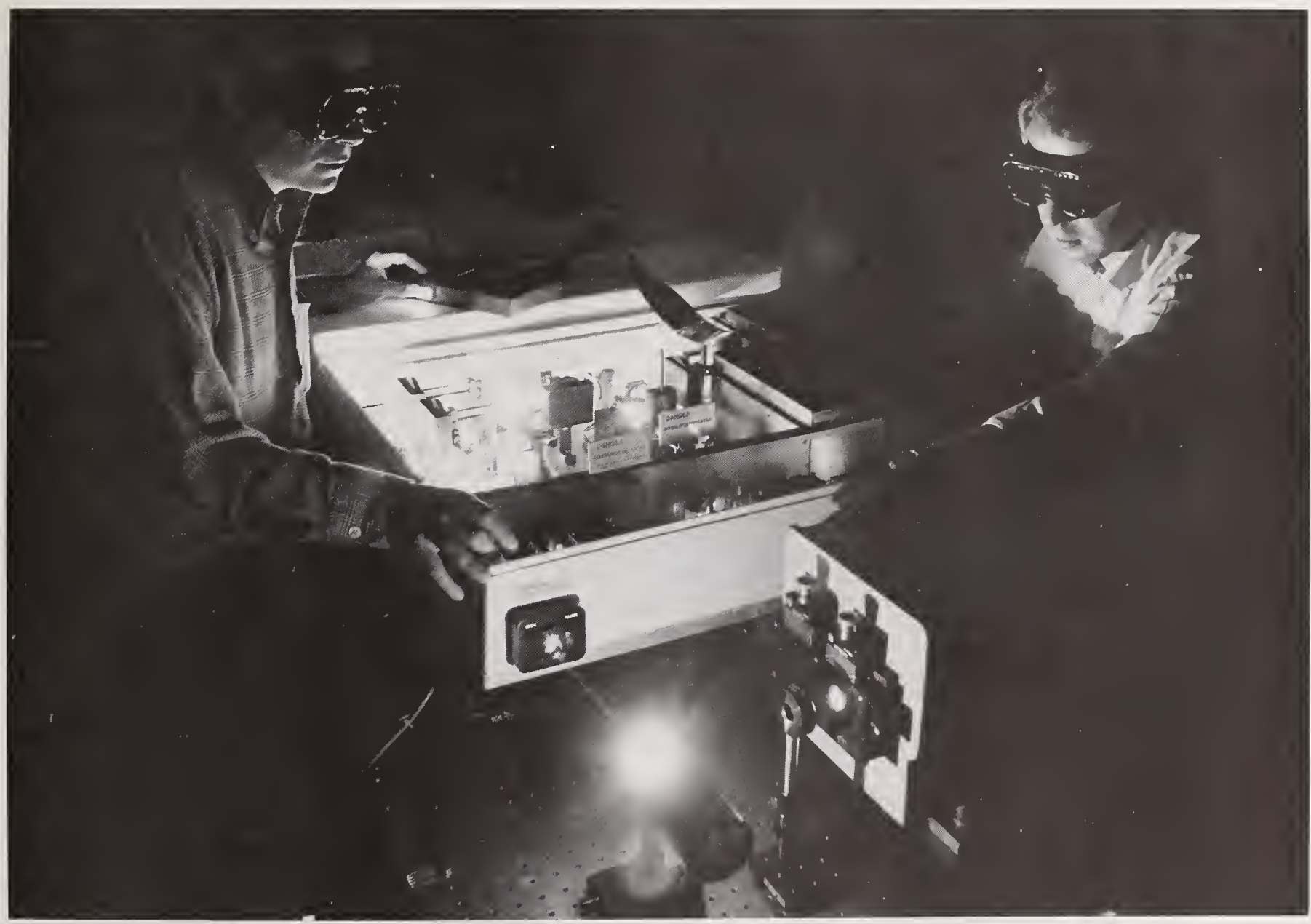

By using laser-induced fluorescence, Dr. John Horvath (left) and Dr. Hratch Semerjian hope to be able to identify and quantify compounds in biochemical reactors.

compound's concentration. Although this technique, called laserinduced fluorescence, has been used for decades to detect simple molecules, researchers have not yet shown that the method works for the large and complex molecules that play key roles in biochemical reactors.

The main advantages of using laser-based measurements to monitor bioreactors are that measurements can be made in minutes, and there is no danger of contaminating the reactor while removing test samples because the laser beam can be directed through a window or optical fiber into the reactor. A laser system will also be cost effective and extremely sensitive to small concentrations of substances, Semerjian says. Such sensitivity is crucial for detecting unwanted by-products in reactors before their concentrations reach damaging levels.

"Effective monitoring of reactors is vital to the commercial application of biotechnology," Semerjian says. "Without it production may be inefficient, which would render products economically

unattractive."

Semerjian has tested a laserinduced fluorescence system and shown that it can discriminate among three amino acids, the building blocks of proteins, at very low concentrations. He plans to test the feasibility of using the system to detect larger molecules closer in size to proteins.

But, even if reactors generate biological products efficiently, there is the additional problem of separating the product from the 


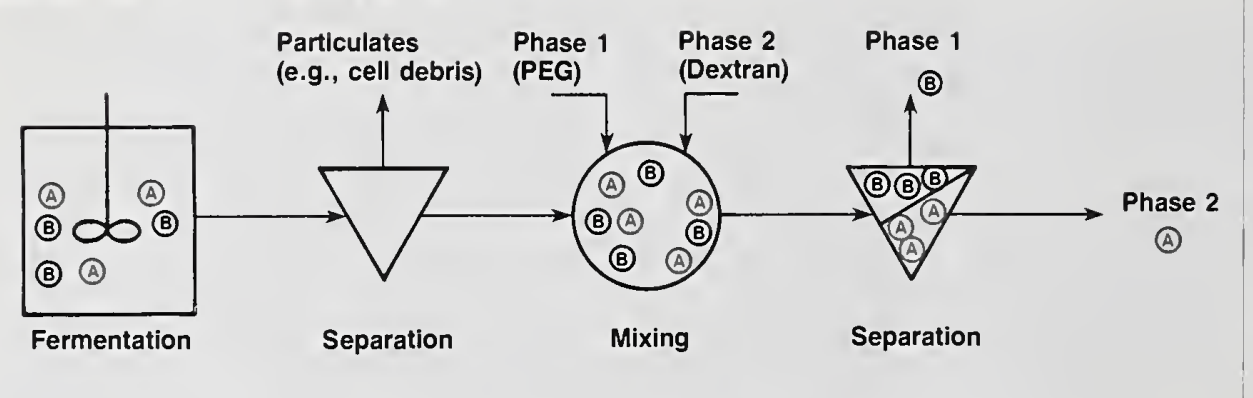

Schematic of the two-phase aqueous extraction technique being evaluated for its efficiency in separating proteins.

cellular debris and by-products in the reactor solution. The desired end product frequently only comprises 1 percent or less of the total solution because higher concentrations are lethal to the microorganisms generating the product.

"Separating a product out of 99 percent water and other impurities is a chemical engineer's nightmare," says NBS chemical engineer Dr. Subhas Sikdar. "Conventional separation techniques such as distillation or filtration cannot separate a product with such a low concentration."

NBS researchers at the Bureau's Boulder, Colo., laboratories are trying to develop innovative techniques to separate biomolecules from solutions at low concentrations. Much of their effort has focused on an elegant technique known as "two-phase aqueous extraction," which relies on a curious phenomenon. Certain combinations of polymers, when dissolved in water in the proper concentrations, create solutions which will not mix with each other even through both are in aqueous solution-a "two-phase solution." One phase is "hydrophilic," the other, "hydrophobic." (The difference has to do with the arrangement of electric charge in the molecules.) If you add a solution of proteins to this, give the mixture a good shake, and wait for the two phases to separate again, the more hydrophilic proteins will migrate to the hydrophilic half of the solution, and the more hydrophobic proteins will move to the hydrophobic half, providing a protein-protein separation which would otherwise be very difficult to do.

Initial tests indicate such a system can efficiently separate two different types of proteins from each other, and NBS researchers plan to assess the efficiency of two-phase aqueous extraction in separating more complex combinations of compounds. They also are determining the various conditions that affect the efficiency of the separation process.

"The advantages of two-phase aqueous extraction are that it can be done at room temperature, which makes it energy efficient; it can be done on a large scale; and proteins are not likely to lose their natural configuration or shape during the process," Sikdar says.

In addition, Sikdar is testing the possibility of using an artificial membrane to separate amino acids, common biotechnology products. The membrane, made primarily of Teflon, is armed with a charge that allows only amino acids to pass through. Also, by altering the acidity of the solution, the membrane can be used to separate basic amino acids from acidic amino acids. The separation can be done at room temperature and pressure so it is energy efficient, Sikdar says.

Sikdar and his colleagues are also measuring the speed at which various proteins travel through aqueous solutions and the solution properties that distort the shape of proteins.

Once the final biotechnology product is generated and separated, its purity must be assured in order for it to be sold. Dr. Dennis Reeder, NBS chemist, and his coworkers hope to aid biotechnology companies in assessing the purity of their products by improving the accuracy of a technique called two-dimensional electrophoresis, which is used to separate and help identify proteins.

With this technique, naturally charged proteins in solution are

\section{Such information is invaluable to biotech- nology companies at- tempting to tailor-make enzymes that will carry out specific reactions.}

separated by their charges when they are passed through a gel column that has a positive electrode on one end and a negative electrode on the other forming a $\mathrm{pH}$ gradient or a range of acidic to basic environments. The gel containing bands of the separated proteins is then put onto a second gel column that separates the proteins by molecular weight.

Because proteins weighing as little as a trillionth of a gram can be detected via two-dimensional electrophoresis, the technique can be used to assess the purity of a 
protein product by visualizing protein contaminants. But twodimensional electrophoresis is a relatively new technique in need of refinement, according to Reeder.

"Two-dimensional electrophoresis is moving from being an art to becoming a science," he says. "There is a great deal of variability between laboratories using this technique."

A number of factors, such as electrode distance, the composition and shelf life of the reagents used, and the temperature at which the procedure was done, can affect the accuracy of the end results, Reeder explains. To counter that variability, Reeder and his colleagues are working on standard methods and reagents for two-dimensional electrophoresis. Other investigators in his group are assessing the factors that affect the protein binding of silver stains used to detect and quantify proteins in electrophoretic gels. In addition, they are developing methods for immobilizing and stabilizing enzymes and proteins.

Reeder is aiding other NBS biotechnology researchers by assessing the stability and purity of the reagents used in their research. The precise measurements made by the NBS Chemical Thermodynamics Division, for example, are only accurate if the compounds they are testing are pure. Investigators within this division are determining how biomolecules react under different temperatures, $\mathrm{pH}$, and electrolyte concentrations. Detailed knowledge of such thermodynamic properties is important for optimizing commercial biotechnology processes.

One important industrial biochemical reaction-the conversion of glucose to fructose-has been studied by NBS chemist Dr. Robert Goldberg and his coworkers. Using a specially designed microcalorimeter and high-performance liquid

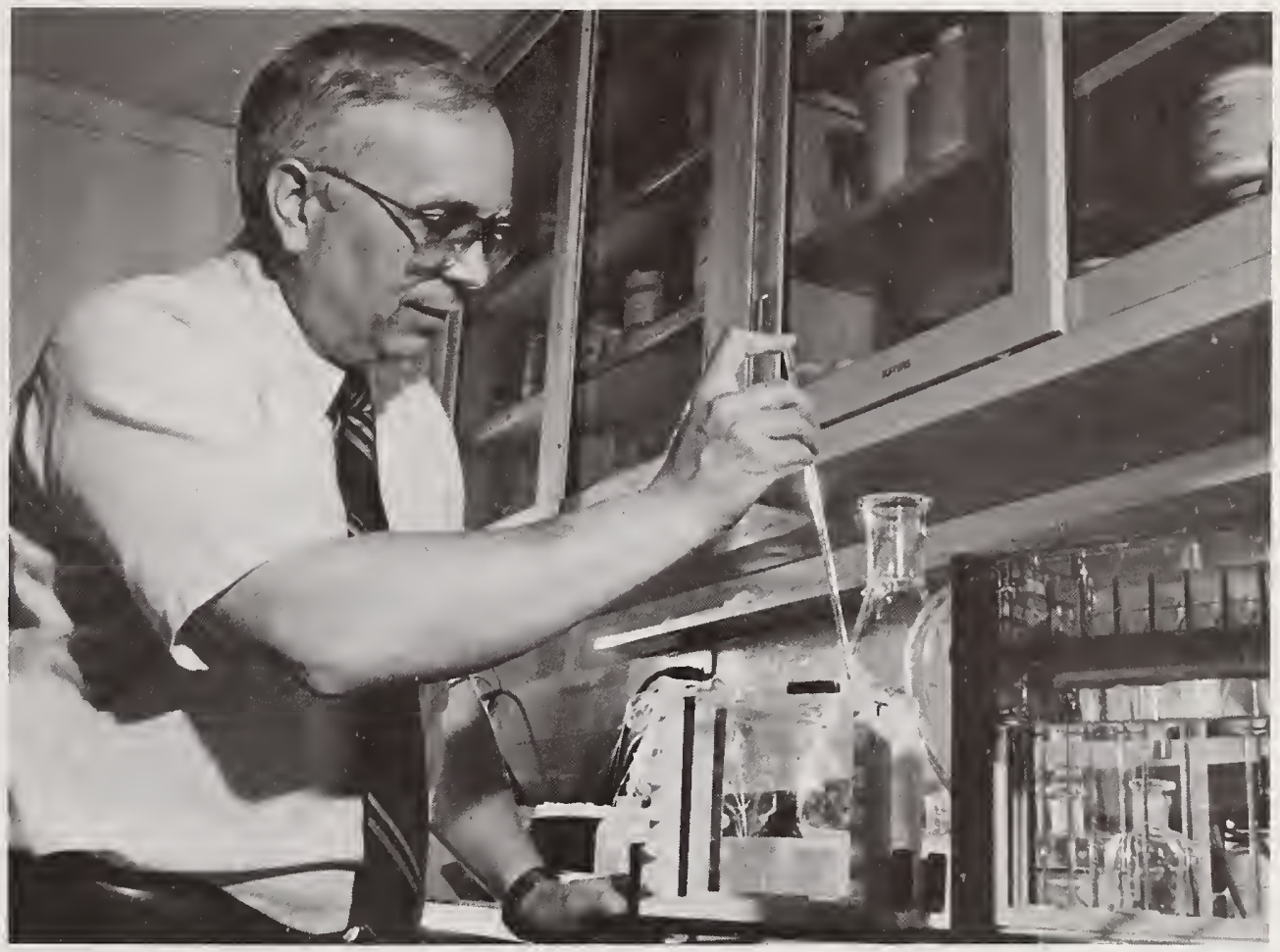

Dr. Dennis Reeder is working to improve the accuracy of two-dimensional electrophoresis so that biotechnology companies can use the technique to assess their products' purity.

chromatography, they measured the amount of heat released and the equilibrium ratio of glucose, a relatively cheap sugar, to fructose, a sweeter sugar widely used in food processing, as the temperature varies. From these data, Goldberg and his coworkers were able to predict reliably how the ratio of glucose to fructose varies with temperature outside the range of measurement-information critical to optimizing the conversion process, which is carried out by an enzyme. This information also allows manufacturers to decide whether it is economically practical to develop enzymes that will work at higher temperatures.

Because some of the most important tools and products of biotechnology are enzymes, NBS physicist Dr. Alexander Wlodawer is trying to use the fine details of various enzyme structures as keys to unlocking how the compounds work. Such information is invaluable to biotechnology companies attempting to tailor-make enzymes that will carry out specific reactions.

To obtain the maximum amount of structural information, Wlodawer uses the techniques of $x$-ray and neutron diffraction, aiming a beam of either $x$ rays or neutrons at a crystallized form of the biomolecule under study. The beam is scattered at different angles and with different intensities depending on the type of atoms it hits and their geometric arrangement. Detectors record the scattering pattern and a computer model is used to 
reconstruct the atomic positions in the molecule.

Because enzymes and other biological materials may contain as many as 10 million individual atoms, it has only been recently that researchers have even attempted to map the detailed chemical structure of biomolecules. Wlodawer and his coworkers completed the first highly refined description of the structure of ribonuclease, an enzyme used in digestion of nucleic acids. They described the atomic positions within the molecule to within .01 to .02 nanometer-the critical size scale or resolution needed to study the motions of individual atoms at the enzyme's active site where reactions take place.

Wlodawer accomplished this feat by combining results from neutron diffraction with $x$-ray diffraction. Neutrons are more strongly scattered by hydrogen, making neutron diffraction an excellent method for determining the position of hydrogen atoms in a molecule. $X$-ray diffraction, on the other hand, depends on the fact that $x$ rays are scattered more strongly by heavier atoms such as metals than by lighter atoms like hydrogen. The two techniques, then, provide complementary information about the type and geometric placement of atoms in a molecule.

Wlodawer is using ribonuclease and other proteins as model systems to devise generic measurement methods that can be applied by other researchers to study the structure of biomolecules Ultimately, he also hopes to uncover the connection between structure and function so that enzymes can be designed to carry out desired reactions efficiently.

NBS quantum chemist Dr. Walter Stevens has similar objectives, but uses different methods. Instead of neutrons and $x$ rays, Stevens' main

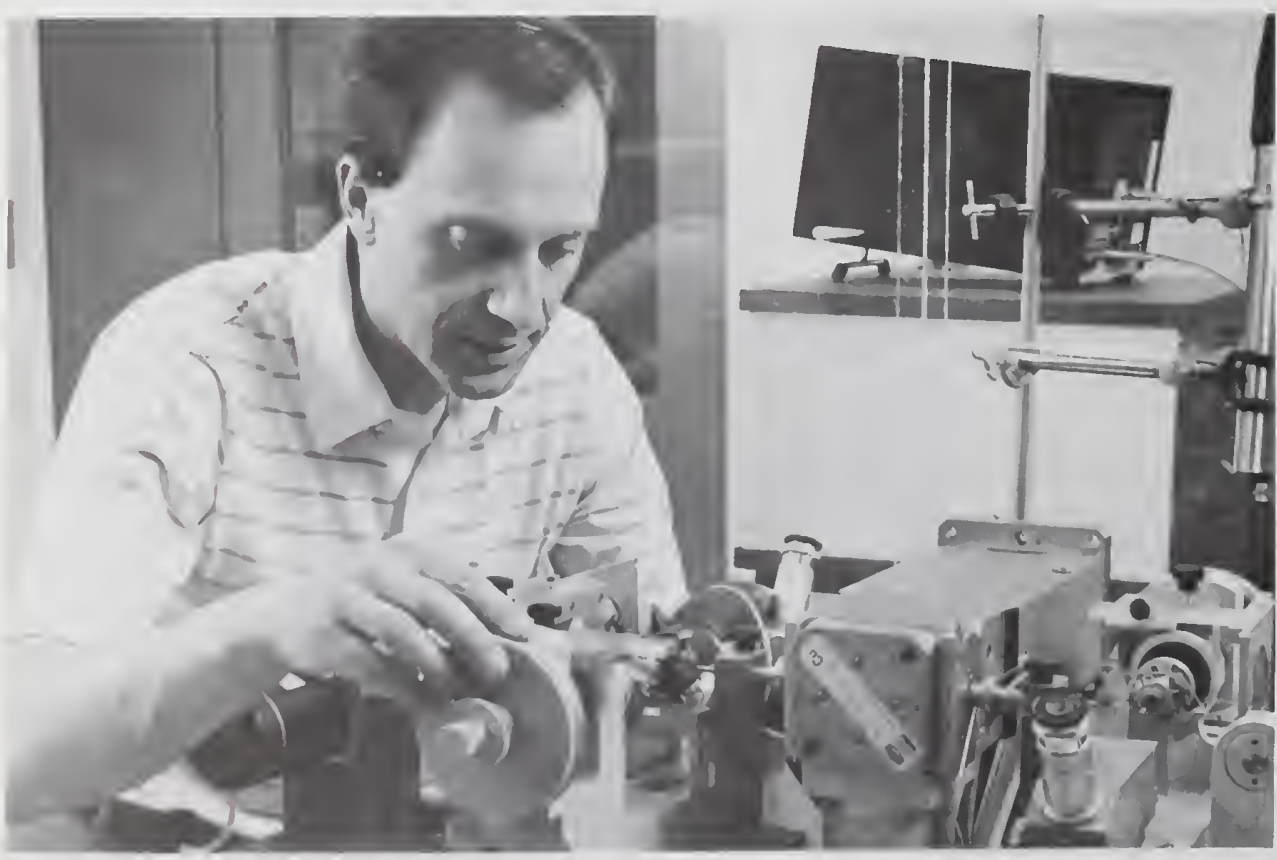

Using several techniques, including $x$-ray diffraction, Dr. Alexander Wlodawer studies enzyme structures to learn more about how they work. tools are equations and high-speed computers. Stevens tries to understand chemical interactions at their most fundamental level by describing the energy states of the molecules involved. Stevens and his colleagues, explains Dr. Pierre Ausloos, director of the NBS Center for Chemical Physics, are theoreticians who use equations to predict

\section{Investigators...are deter- mining how biomolecules react under different tem- peratures, $\mathrm{pH}$, and electrolyte concentrations.}

the outcome of chemical reactions. These equations mathematically model the behavior and energy states of individual atoms and molecules. Equations used to describe even the simplest bonding patterns between two atoms are so complex that high-speed computers are needed to carry out the calculations.

Biotechnology is a relatively new application for quantum chemistry, according to Stevens, because of the large size of biomolecules. Rather than take on whole molecules at once, quantum chemists study individual molecular frag ments that make up the whole NBS researchers are calculating the strength of chemical bonds between active sites of enzymes and particular molecules, for example. A small change in the atomic composition of the active site could either speed up the reaction or prevent it from happening at all. By helping to understand the effects of subtle changes in either the active site of an enzyme or in the molecule it is reacting with, Stevens and his colleagues can often minimize the time and expense needed for actual laboratory experimentation.

In the future, they want to investigate larger molecular groups using molecular mechanics and reaction field techniques. By approximating 


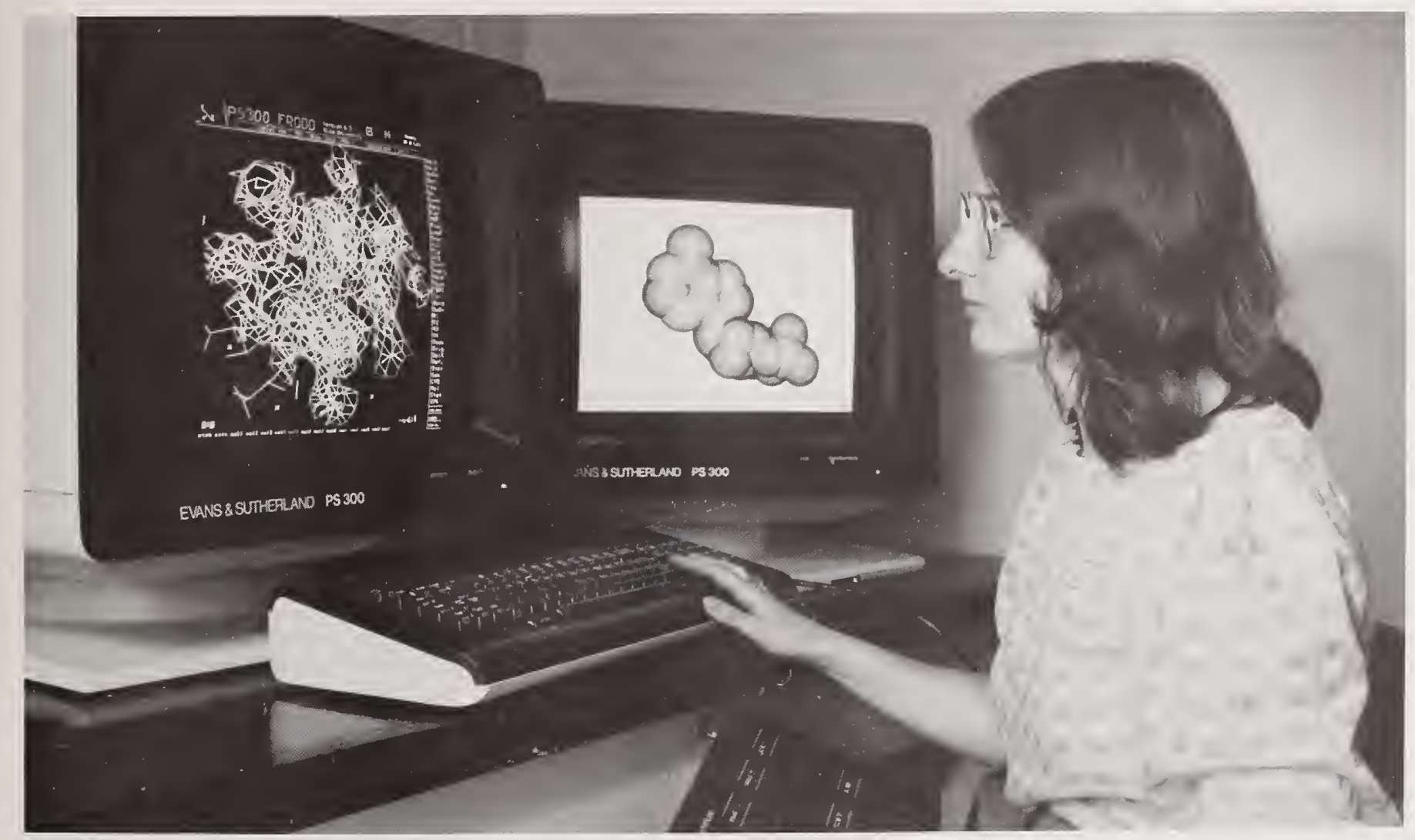

\section{Using experimental data and sophisticated computers, Dr. Irene Weber maps the detailed chemical structure of biomolecules to determine how they can be tailor-made to carry out specific reactions.}

some information which is dealt with explicitly in quantum mechanics, molecular mechanics is capable of describing the energy levels and bonding patterns of much larger molecular groups. While quantum mechanics is limited to a few dozen atoms at a time, molecular mechanics can be used to study groups containing hundreds of atoms, but at a lower level of accuracy.

"What we really need is a way to combine the quantum mechanics with less accurate methods so that the important active sites of the biomolecules can be studied in a realistic molecular environment rather than as simple fragments," says Stevens. To make their calculations more realistic, these researchers are developing a new theoretical tool called the "reaction field" method. In this method, the quantum mechanical equations describing the active site are modified to account for the influence of the remaining parts of the molecule.

The non-active parts of the molecule provide a "reaction field" in which the chemistry at the active sites takes place. By including the reaction field in a study of the active site, molecules containing up to 1,000 atoms may be studied theoretically.

The group uses a computer to do these large calculations and to produce three-dimensional displays of biomolecules and processes under study. Three-dimensional graphic displays of molecules, explains Stevens, are helpful in visualizing how the structure of a molecule is related to its function and in collaborative studies with experimentalists like Wlodawer.

The combined efforts of the researchers at NBS should help the burgeoning biotechnology industry use nature to its advantage in generating commercially useful products. "It's

exciting to work in this area," says Semerjian, "because our work can have such a large impact on a wide range of fields from fuel to vaccine production."

by Margie Patlak

Milwaukee, Wisconsin-based

Science Writer 


\section{DIRECTORY OF FEDERAL CERTIFICATION PROGRAMS FOR PRODUCTS AND SERVICES}

Toth, R.B., Federal Government Certification Programs for Products and Services, Natl. Bur. Stand. (U.S.), NBS Spec. Pub. 714, 157 pages (April 1986). Order by stock no. 003-003-02719-7 from GPO, \$8 prepaid.

The federal government's certification programs cover a wide variety of goods and services including manufactured products, agricultural commodities, medical devices and drugs, and defense procurement. This directory, which can be used by manufacturers, distributors, state and local government officials, consumers, and others concerned with the standards and procedures used in federal certification programs, contains information on 61 of these programs. Each entry describes the scope and nature of the program, the testing and inspection practices, standards used, methods of identification and enforcement, reciprocal recognition or acceptance of certification, as well as other relevant information.

This publication is the second of a threepart series which includes a directory of private sector product certification programs (NBS Spec. Pub. 703) and a companion volume on state programs now being compiled to complete the series. For more information on the certification programs, standards, and standards-related subjects, contact: Standards Code and Information, Office of Product Standards Policy, A629 Administration Building, NBS, Gaithersburg, MD 20899, 301/921-2092.

\section{FUNDAMENTAL INTERACTIONS WITH COLD NEUTRONS}

Greene, G.L., The Investigation of Fundamental Interactions with Cold Neutrons, Natl. Bur. Stand. (U.S.), NBS Spec. Pub. 711, 163 pages (February 1986). Order by stock no. 003-003-02718-9 from GPO, $\$ 8.50$ prepaid.

NBS has published the proceedings of a November 1985 workshop on the use of cold (slow) neutrons to study the properties of fundamental interactions of particles. More than 50 researchers from 23 institutions in North America and Europe attended to review current research and to propose future work. The results are important to fields such as the theory of the weak interaction, nuclear theory, astrophysics, and theories of invariance laws and symmetry principles. The workshop was sponsored by NBS and the Department of Energy to gather information for use in planning research efforts at the coldneutron source now being developed at the NBS research reactor.

\section{FEDERAL STANDARD FOR ADA}

Ada, Natl. Bur. Stand. (U.S.), FIPS PUB 119 (November 1985). Order by title and FIPS PUB 119 from NTIS, \$23 prepaid (includes the American National Standards Institute specifications document).

\section{A federal standard for the computer} program language Ada is now available and has been approved for federal government use by Commerce Secretary Malcolm Baldrige. Ada is a high-level language suitable for use in programming applications such as control of real-time processes or parallel processing; very large systems where correct modularization is crucial; systems which need to be very reliable; and systems which are to be developed with reusable software packages. The Federal Information Processing Standard, which became effective May 1 , 1986, adopts a voluntary industry standard issued by the American National Standards Institute. A transition period beginning on the effective date and continuing 1 year will provide time for industry to produce $\mathrm{Ada}$ processors conforming to the standard.

\section{TECHNICAL ACTIVITIES OF THE CENTER FOR CHEMICAL ENGINEERING}

Hord, J., editor, Center for Chemical Engineering Technical Activities: Fiscal Year 1985, Natl. Bur. Stand. (U.S.), NBSIR 85-3039, 160 pages (February 1986). Order by stock no. PB 86-166295 from NTIS, $\$ 16.95$ prepaid.

The NBS Center for Chemical Engineering focuses its research on support of the chemical and related industries, including the chemical, petrochemical, petroleum, gas, paper, biochemical, energy, and food and drug sectors. It provides the fundamental scientific framework for reliable measurement and databases that assures equity in domestic and international trade and enables improved innovation, design, and control of chemical processes. Descriptive summaries of the research projects, including objectives, progress, publications, and staff are included in this report.

\section{PROCEEDINGS FROM ACCESS TO JAPANESE LITERATURE SEMINAR} Brady, EL., editor, U.S. Access to Japanese Technical Literature: Electronics and Electrical Engineering, Natl. Bur. Stand. (U.S.), NBS Spec. Pub. 710 , 155 pages (January 1986). Order by stock no. 003-003-02709-0 from GPO, $\$ 6$ prepaid.

How can the United States gain better access to Japanese technical literature in electronics and electrical engineering? A June 1985 seminar held at NBS focused on this question and the resulting publication offers transcripts of presentations by representatives from Congress, industry, universities, and federal agencies. The common thread in the presentations was interest in maintaining current knowledge of technical progress in Japan despite frustration over language barriers. Few Americans can read Japanese and only about 20 percent of Japanese technical literature is routinely published in English. This raises questions such as: How important is the 20 percent available in English? How can one gain access to the other 80 percent? The seminar offered possible answers, including a more active translation role for professional societies as well as support from American industry. 


\section{REVISED INDEX OF U.S. VOLUNTARY ENGINEERING STANDARDS}

National Center for Standards and Certification Information Staff, Key-Word-InContext (KWIC) Index of U.S. Voluntary Engineering Standards, Natl. Bur. Stand. (U.S.) (January 1986). Order microfiche copies only by title and stock no. PB 86154408 from NTIS, $\$ 13.50$ prepaid.

Manufacturers, exporters and importers, and others concerned with standards developed by U.S. trade associations and technical and professional societies will be interested in the revision of this index. It contains more than 28,000 titles of standards, specifications, test methods, and recommended practices published by 422 U.S. standards-developing organizations. First published in 1971, the revised microfiche index provides the title, date, source, and number of the standard for each entry. Titles can be found by all of the significant keywords they contain. For information on the KWIC index, contact the Standards Code and Information Office, A629 Administration Building, NBS, Gaithersburg, MD 20899, 301/921-2092.

\section{PROPER USE OF PASSWORDS FOR COMPUTER SECURITY}

Password Usage, Natl. Bur. Stand. (U.S.), FIPS PUB 112, 56 pages (May 1985). Order by title and FIPS PUB 112 from NTIS, $\$ 9.95$ prepaid.

Passwords have been used for centuries as a way to prove one's right to access or information. Today, they commonly are used to deter unauthorized access to computer systems and networks. While they are not the only method of authentication, nor necessarily the best, if properly used, passwords can provide reasonable deterrence. Federal Information Processing Standard (FIPS) Publication 112 describes basic security criteria for using passwords in computer systems. (FIPS are published by NBS for use by the federal government.) The standard discusses 10 factors to be considered in establishing password systems: composition, length, lifetime, source, ownership, distribution, storage, entry, transmission, and authentication period. Approved last year and recently issued, the standard took effect June 1 , 1986.

\section{ANNUAL DIRECTORY FOR NVLAP LABORATORIES}

Berger, H.W., editor, 1985-86 NVLAP Directory of Accredited Laboratories, Natl. Bur. Stand. (U.S.), NBSIR 86-3315, 117 pages (January 1986). Order by stock no. PB 86-158003 from NTIS, $\$ 16.95$ prepaid.

NBS has published the annual directory for the National Voluntary Laboratory Accreditation Program (NVLAP), which is administered by the Bureau. The directory provides indexes to more than 140 laboratories nationwide that are accredited in one or more areas of testing. The indexes include a list of laboratories by name and NVLAP code number, test methods, accreditation program, and geographical location of each laboratory. There are laboratory accreditation programs for thermal insulation; ready-mixed field concrete; carpets; solid-fuel room heaters; acoustical testing services; processors of personal radiation dosimeters; and commercial products (paper and paper products, paints and related coatings and materials, and mattresses). Laboratories that test photographic film, seals and sealants, and electromagnetic and telecommunications equipment are also included

\section{EVALUATION OF HEAT DETECTORS BY COMPUTER PROGRAM}

Stroup, D.W., Evans, D.D., and Martin, P., Evaluating Thermal Fire Detection Systems [English Units], Natl. Bur. Stand. (U.S.), NBS Spec. Pub. 712, 557 pages (April 1986). Order by stock no. 003-003-02727-8 from GPO, \$25 prepaid.

Researchers in the NBS Center for Fire Research have developed a computer program to evaluate heat detection systems installed in existing buildings. Depending on ceiling height, spacing of detectors, type of detector, and how fast the fire grows, the program will determine how long it will take for the detector to be activated. The user-friendly program is available in both BASIC and FORTRAN and will run on mainframes as well as personal computers. In addition, the FORTRAN version was used to generate an extensive set of tables (included) which can be used to quickly evaluate response time of common systems.

\section{ANALYTICAL CHEMISTRY ACTIVITIES REPORT}

Durst, R.A., Hert, H.S., and Taylor, J.K., editors, Technical Activities

1985-Center for Analytical Chemistry, Natl. Bur. Stand. (U.S.), NBSIR 85-3272, 182 pages (November 1985). Order from the Center for Analytical Chemistry, A309 Chemistry Building, National Bureau of Standards, Gaithersburg, MD 20899, 301/921-2851.

The measurement of vitamins in blood serum to determine their role in preventing cancer, the analysis of trace elements in foods, and the measurement of toxic gases at the parts per billion level are just a few of the programs described in this NBS report. The document gives capsule summaries of 1985 research in the three major divisions-inorganic analytical, organic analytical, and gas and particulate science-within the Bureau's Center for Analytical Chemistry. Major publications and activities are listed, along with tallies of analytical chemistry Standard Reference Materials produced by the center in 1985 (These materials, sold by NBS, are widely used by industries such as metals and chemicals as well as in clinical and environmental laboratories to improve analytical measurements.) The report also reflects basic research on new measurement techniques and analytical chemistry's burgeoning role in providing data for highly complex sample types-samples such as hazardous chemical and nuclear wastes, body fluids, plant and animal tissues, foods, and high-technology materials.

\section{ORDERING INFORMATION}

To order publications from NTIS, send request with payment to: National Technical Information Service, Springfield, VA 22161 Publications can be ordered from GPO by mailing order with payment to

Superintendent of Documents, U.S. Government Printing Office, Washington, DC 20402. 
10th Triennial Congress of the International Council for Building Research, Studies, and Documentation (CIB), Convention Center, Washington, DC

\section{September 21-26, 1986}

This congress will provide participants an opportunity to discover some of the most important innovations in building practices, research, and development. Over 500 experts in various building-related fields from around the world will deliver presentations addressing issues in the areas of advancing building technology for the computer age; shelter for the homeless in developing nations; and translating research into practice. Topics within these areas include: performance and durability of materials; automated building systems; integration of information for building projects; incentives, finance, and economics; national and international shelter programs; and robotics in construction. Sponsored by the Building Research Board of the National Research Council of the National Academies of Sciences and Engineering and NBS. Contact: Noel J. Raufaste, CIB.86 Director, B226 Building Research Building, NBS, Gaithersburg, MD 20899, 301/921-3106.

\section{Meeting of the National Conference of Standards Laboratories, 25 Years of Measurement Progress, NBS, Gaithersburg, MD \\ October 6-9, 1986}

Emphasis at this conference will be on new developments in metrology and new management techniques to efficiently utilize resources, as well as the emerging role of the metrologist in contributing to improved product quality and reliability. In addition, the program will give timely recognition to the pioneers of measurement science and will take a look at the progress in measurement science over the past 25 years. Workshops will include special hands-on sessions to keep the metrology manager and engineer abreast of technological advances and new innovative ideas. Since the Natıonal Conference of Standards Laboratories (NCSL) will be celebrating its 25th anniversary during
1986, the program will include a special session dealing with the history and progress of the organization. Sponsored by NCSL and NBS. Contact: Ernest L. Garner, B362 Physics Building, NBS, Gaithersburg, MD 20899, 301/921-2805.

\section{Thirty-Second Annual Conference on Bioassay, Analytical, and Environmental Radiochemistry, NBS, Gaithersburg, MD October 21-23, 1986}

The ability to quantify minute amounts of radionuclides in a variety of difficult matrices continues to be important for the study and protection of humans and the environment. In this informal conference, researchers and analysts from government, industry, and academia will discuss new, improved, or even problem analytical methods, interprel subsequent data, and evaluate health and environmental implications. The scope for the conference will include in vivo and in vitro bioassay, analytical method development, distribution and partition of radionuclides in the environment, and modeling and health significance of radionuclide pathways to humans. Sponsored by NBS, the U.S. Environmental Protection Agency, the U.S. Nuclear Regulatory Commission, and the U.S. Department of Energy. Contact: Dr. Kenneth Inn, C114 Radiation Physics Building, NBS, Gaithersburg, MD 20899 , 301/921-2383.

\section{Annual Conference on Fire Research, NBS, Gaithersburg, MD}

November 3-7, 1986

This conference sponsored by the NBS Center for Fire Research (CFR) will promote scientific exchange among technical peer groups in five fire research areas-fire growth, material combustion science and measurement, combustion product generation and impact, modeling and measuring fire-generated environments and hazards, and extinction. Within this context, the CFR in-house and research grant programs will be presented, as well as a limited number of outside projects. Discussion of new ideas, further research needs, and technical priorities will also be encouraged. Contact Sonya Cherry, A247 Polymer Building, NBS, Gaithersburg, MD 20899, 301/921-3845.
1986 International Workshop on Moisture Measurement and Control for Microelectronics, NBS, Gaithersburg, MD

November 12-14, 1986

The increasing use of organic materials in hybrid, VLSI, and VHSIC packages, the attractive use of lower-cost plastic parts, together with the inevitable presence of moisture in the packaging environment challenge component reliability. In order to point out the effects of moisture on microelectronics and to review the stateof-the-art in the means to better measure and control a package moisture rate, this fourth workshop will provide a wide international forum for exchange of information and ideas among analysts, semiconductor manufacturers, users, and others interested in packaging reliability. Sponsored by the Rome Air Development Center and NBS. Contact: Stanley Ruthberg, A331 Technology Building, NBS, Gaithersburg, MD 20899, 301/921-3625.

Scientific Software for Supercomputing, NBS, Gaithersburg, MD

November 17-20, 1986

Potential users of supercomputers need to learn about how supercomputing relates to their problems, and they need hands-on training in the effective use of supercomputing facilities. Experience has shown that merely providing supercomputer machine cycles does not give sufficient motivation to get scientists involved in more sophisticated calculations using supercomputers. This workshop will answer the users' needs by providing participants with some of the background and tools necessary to effectively use supercomputer resources. The workshop will present case studies, which will be combined with tutorials, and workshops that will provide hands-on training. Sponsored by NBS and the Society for Industrial and Applied Mathematics. Contact: Dr. Francis E. Sullivan, A151 Technology Building. NBS, Gaithersburg, MD 20899, 301/921. 3395. 
he National Bureau of Standards was established by an act of Congress on March 3, 1901. The Bureau's overall goal is to strengthen and advance the nation's science and technology and facilitate their effective application for public benefit. To this end, the Bureau conducts research and provides: (1) a basis for the nation's physical measurement system; (2) scientific and technological services for industry and government; (3) a technical basis for equity in trade; and (4) technical services to promote public safety. The Bureau's technical work is performed by the National Measurement Laboratory, the National Engineering Laboratory, the Institute for Computer Sciences and Technology, and the Institute for Materials Science and Engineering.

\section{THE NATIONAL MEASUREMENT LABORATORY}

Provides the national system of physical and chemical measurement; coordinates the system with measurement systems of other nations and furnishes essential services leading to accurate and uniform physical and chemical measurement throughout the nation's scientific community, industry, and commerce; provides advisory and research services to other government agencies; conducts physical and chemical research; develops, produces, and distributes Standard Reference Materials; and provides calibration senvices. The laboratory consists of the following areas:

- Standard Reference Data

- Measurement Services

- Basic Standards

- Radiation Research

- Chemical Physics

- Analytical Chemistry

\section{THE NATIONAL ENGINEERING LABORATORY}

Provides technology and technical services to the public and private sectors to address national needs and to solve national problems; conducts research in engineering and applied science in support of these efforts; builds and maintains competence in the necessary disciplines required to carry out this research and technical service; develops engineering data and measurement capabilities; provides engineering measurement traceability services; develops test methods and proposes engineering standards and code changes; develops and proposes new engineering practices; and develops and improves mechanisms to transfer results of its research to the ultimate user. The laboratory consists of the following centers:

- Applied Mathematics

- Electronics and Electrical Engineering

- Manufacturing Engineering

- Building Technology

- Fire Research

- Chemical Engineering

\section{THE INSTITUTE FOR COMPUTER SCIENCES AND TECHNOLOGY}

Conducts research and provides scientific and technical services to aid federal agencies in the selection, acquisition, application, and use of computer technology to improve effectiveness and economy in government operations in accordance with Public Law 89-306 (40 U.S.C. 759), relevant Executive Orders, and other directives; carries out this mission by managing the Federal Information Processing Standards Program, developing federal ADP standards guidelines, and managing federal participation in ADP voluntary standardization activities; provides scientific and technological advisory services and as- sistance to federal agencies; and provides the technical foundation for computer-related policies of the federal government. The institute consists of the following centers:

- Programming Science and Technology

- Computer Systems Engineering

\section{THE INSTITUTE FOR MATERIALS SCIENCE AND ENGINEERING}

Conducts research and provides measurements, data, standards, reference materials, quantitative understanding, and other technical information fundamental to the processing, structure, properties, and performance of materials; addresses the scientific basis for new advanced materials technologies; plans research around cross-country scientific themes such as nondestructive evaluation and phase diagram development; oversees Bureau-wide technical programs in nuclear reactor radiation research and nondestructive evaluation; and broadly disseminates generic technical information resulting from its programs. The institute consists of the following divisions:

- Nondestructive Evaluation

- Inorganic Materials

- Fracture and Deformation

- Polymers

- Metallurgy

- Reactor Radiation 
